\title{
Palladacycles: Effective Catalysts for a Multicomponent Reaction with Allylpalladium(II)-Intermediates
}

\author{
Atsushi Shiota and Helena C. Malinakova* \\ Department of Chemistry, The University of Kansas, 1251 Wescoe Hall Drive, Lawrence, Kansas \\ 66045
}

\begin{abstract}
Palladium(II) complexes with an auxiliary bidentate ligand featuring one C-Pd bond and a Pd-Ndonor bond (palladacycles) have been shown to afford improved yields of homoallylic amines from a three-component coupling of boronic acids, allenes and imines in comparison to the yields of homoallylic amines achieved with the originally reported catalyst $\left(\mathrm{Pd}(\mathrm{OAc})_{2} / \mathrm{P}(t-\mathrm{Bu})_{3}\right)$, thus extending the scope of the reaction. ${ }^{31} \mathrm{P}$ NMR monitoring studies indicate that distinct intermediates featuring Pd-P bonds originate in the reactions catalyzed by either $\mathrm{Pd}(\mathrm{OAc})_{2} / \mathrm{P}(t-$ $\mathrm{Bu})_{3}$ or the pallada(II)cycle/P( $\left.t-\mathrm{Bu}\right)_{3}$ systems, suggesting that the role of the pallada(II)cycles is more complex than just precatalysts. The importance of an additional phosphine ligand in the reactions catalyzed the pallada(II)cycles was established, and its role in the catalytic cycle has been proposed. Insights into the nature of the reactive intermediates that limit the performance of the originally reported catalytic systems has been gained.
\end{abstract}

\section{Keywords \\ palladacycles; cyclopalladation; allylpalladium complex; three-component coupling reaction; catalytic intermediate}

\section{Introduction}

\begin{abstract}
Since the first reports on the isolation of cyclopalladated complexes [1], sometimes called palladacycles featuring bidentate ligands with a general structure $\mathrm{C}-\mathrm{X}(\mathrm{X}=\mathrm{N}, \mathrm{P}, \mathrm{S}$ etc), numerous studies assessing the performance of these palladium(II) complexes as catalysts in traditional palladium-catalyzed reactions, including Heck reactions and cross-coupling protocols were published [2]. Extensive discussions of different mechanistic possibilities [3] appear to converge on the notion that palladacycles operate as precatalysts that give rise to low concentrations of palladium(0), rather than engaging in catalytic cycles with $\mathrm{Pd}(\mathrm{II}) /$ $\operatorname{Pd}(\mathrm{IV})$ intermediates [4]. Recently, novel palladium-catalyzed reactions under oxidative conditions have been shown to involve palladacycles as key intermediates. In these protocols, substrates undergo cyclopalladation yielding pallada(II)cycles, which are then
\end{abstract}

\footnotetext{
(C) 2012 Elsevier B.V. All rights reserved.

*Corresponding author. Tel.: 1785864 4743; fax: 1785864 5396. hmalina@ku.edu.

Publisher's Disclaimer: This is a PDF file of an unedited manuscript that has been accepted for publication. As a service to our customers we are providing this early version of the manuscript. The manuscript will undergo copyediting, typesetting, and review of the resulting proof before it is published in its final citable form. Please note that during the production process errors may be discovered which could affect the content, and all legal disclaimers that apply to the journal pertain.

Appendix A. Supplementary material

Full page ${ }^{1} \mathrm{H}$ NMR and ${ }^{13} \mathrm{C}$ NMR spectra for compounds 4a-g and detailed description of the ${ }^{31} \mathrm{P}$ NMR monitoring experiments discussed in the text, as well as the description of additional control experiments.
} 
oxidized to $\mathrm{Pd}(\mathrm{IV})$ complexes poised to release functionalized substrates via a reductive elimination [5].

In contrast, palladium-catalyzed reactions in which cyclopalladated ligands in pallada(II)cycles function as true auxiliary ligands throughout the catalytic cycle remain rare [6]. A catalytic asymmetric aza-Cope reaction described by Overman represents an example of such a process [6a]. Grigg has employed a $\mathrm{Pd}(\mathrm{II})$ catalyst bearing a cyclopalladated auxiliary ligand to catalyze an annulation reactions involving an intramolecular allylation of aldehydes and ketones [6b]. Szabo pioneered the application of (PCP) palladium(II) pincer complexes in allylations of aldehydes and imines with trifluoro(allyl)borates [6c].

Herein, we report that pallada(II)cycles featuring $\mathrm{C}-\mathrm{X}\left(\mathrm{X}=\mathrm{Nsp}^{2}\right.$ or $\left.\mathrm{Nsp}^{3}\right)$ chelates effectively catalyze a three-component coupling reaction of boronic acids $\mathbf{I}$, allenes II and imines III yielding highly substituted homoallylic amines IV (Fig. 1) recently described [7] by the author's laboratory. The structure-activity relationship for the auxiliary $\mathrm{C}-\mathrm{X}$ ligand in the catalysts have been surveyed, and the optimum pallada(II)cycle catalyst provided improved yields of homoallylic amines IV in comparison to the previously reported palladium catalyst $\left(\mathrm{Pd}(\mathrm{OAc})_{2}\right)$ in reactions featuring heteroatom-substituted boronic acids $\mathbf{I}$. The importance of additional phosphine ligand in the reactions catalyzed the pallada(II)cycles was established, and its role in the catalytic cycle has been proposed. Mechanistic experiments utilizing ${ }^{31} \mathrm{P}$ NMR monitoring suggested that the pallada(II)cyclebased catalysts did not give rise to intermediates common with the reactions catalyzed by $\mathrm{Pd}(\mathrm{OAc})_{2}$. Furthermore, the ${ }^{31} \mathrm{P}$ NMR monitoring provided insights into the nature of the reactive intermediates limiting the scope of the originally reported catalytic system.

\section{Results and discussion}

The original report from our laboratories on the preparation of homoallylic amines IV via palladium catalyzed three-component coupling identified $\mathrm{Pd}(\mathrm{OAc})_{2} / \mathrm{P}(t-\mathrm{Bu})_{3}(\mathrm{Pd}: \mathrm{P}=1: 1)$ as the catalyst of choice [7a]. The allylpalladium(II) complex $\mathbf{V}$, existing as equilibrium between complexes $\mathbf{V a}$ and $\mathbf{V b}$ (path (b) in Fig. 2) and arising via a sequential B to Pd transmetalation, allene migratory insertion and a second transmetalation (path (a) in Figure 2) was proposed as the key intermediate. Complex $\mathbf{V}$ then reacts with imine (path (c) in Fig. 2) giving rise to a $\eta^{1}$-bonded allylpalladium(II) complex involved in the nucleophilic allyl transfer providing the homoallylic amine (path (d) in Fig. 2) [7,8]. A complete catalytic cycle for the reactions catalyzed by $\mathrm{Pd}(\mathrm{OAc})_{2}$ including the product release step (path (e) in Fig. 2) is shown in Fig. 2.

Aiming to identify more robust and broader-scope palladium(II) catalysts for this reaction, we set out to explore the performance of cyclopalladated $\mathrm{Pd}(\mathrm{II})$ dimers bearing $\mathrm{C}-\mathrm{X}(\mathrm{X}=\mathrm{N}$, $\mathrm{S}, \mathrm{P}$ ) chelates. We reasoned that allylpalladium(II) complexes VI existing as equilibrium between complexes VIa and VIb and closely analogous to the originally proposed nucleophilic allylpalladium(II) intermediates $\mathbf{V}$ would arise from the cyclopalladated complexes by a shorter sequence of B to Pd transmetalation (path (a) in Fig. 3) and allene migratory insertion (path (b) in Fig. 3). A subsequent complexation of the imine to form complex VII (path (c) in Fig. 3) and the nucleophilic allyl transfer would deliver the homoallylic amines in a manner analogous to the catalytic cycle shown in Fig. 2. However, it will have to be ascertained by experimentation whether the pallada(II)cyclic catalyst is capable of mediating the nucleophilic allyl transfer, since the only relevant precedents involve a rather specific intramolecular 5-exo-trig cyclization event reported by Grigg [6b], and a nucleophilic allyl transfer from a $\mathrm{Pd}(\mathrm{II})$ complex bearing a tricoordinate pincer ligand [6c] that effectively forces the requisite $\eta^{1}$-bonding $[8,9]$ of the allyl fragment. 
Thus, the reaction of boronic acid 1a, allene $\mathbf{2}$ and imine $\mathbf{3 a}$ catalyzed by cyclopalladated dimer $\mathbf{A}(10 \mathrm{~mol} \% \mathrm{Pd})$ under conditions (1a : $\mathbf{2}: \mathbf{3}, 2: 5: 1 \mathrm{~mol}$ equiv, THF, $\left.40{ }^{\circ} \mathrm{C}, 16 \mathrm{~h}\right)$ otherwise optimized for the $\mathrm{Pd}(\mathrm{OAc})_{2} / \mathrm{P}(t-\mathrm{Bu})_{3}$ catalyst was investigated (Scheme 1). In all cases, a single diastereomer of the amine $\mathbf{4 a}$, identical to the diastereomer obtained under the originally reported conditions and assigned as anti [7a], was obtained in the experiments reported in Scheme 1 and Table 1 (vide infra). Unexpectedly, the addition of a phosphine ligand was required in order to achieve optimum performance of the catalyst. The most sterically demanding phosphines $\mathrm{P}(t-\mathrm{Bu})_{3}$ and $\mathrm{PPh}(t-\mathrm{Bu})_{2}$ delivered as $\mathrm{HP}(t-\mathrm{Bu})_{3} \mathrm{BF}_{4}$ and $\mathrm{HPPh}(t-\mathrm{Bu})_{2} \mathrm{BF}_{4}$ afforded the best yields of amine $\mathbf{4 a}(76 \%$ and $73 \%$, respectively), in comparison to $\mathrm{P}(o-\mathrm{Tol})_{3}(18 \%)$ and $\mathrm{PPh}_{3}(44 \%)$ ligands (Scheme 1). Notably, the yield of amine $4 a$ obtained with the cyclopalladated catalyst $\mathbf{A}(76 \%)$ was indeed higher than the yield ever achieved with the originally reported $\mathrm{Pd}(\mathrm{OAc})_{2} / \mathrm{P}(t-\mathrm{Bu})_{3}$ catalyst $(61 \%)[7 \mathrm{a}]$. The reaction mixtures with catalyst $\mathbf{A}$ did not show apparent signs (color change or precipitation) of the formation of $\mathrm{Pd}(0)$ noted in the $\mathrm{Pd}(\mathrm{OAc})_{2}$-catalyzed reactions, although an aryl-aryl coupling side reaction was detected in both systems.

Next, the performance of a series of cyclopalladated dimer complexes B-L (Fig. 4) as catalysts for the preparation of amine $\mathbf{4 a}$ under the conditions optimized with the pallada(II)cycle A was evaluated (Table 1). In general, cyclopalladated complexes A-H [10] possessing the $\mathrm{C}-\mathrm{N}$ chelate in the auxiliary ligands proved to be viable catalysts affording amine 4a in yields higher than 50\% (entries 2, 3 and 5-9, Table 1). However, none of the complexes performed better than complex $\mathbf{A}$ or the originally reported $\mathrm{Pd}(\mathrm{OAc})_{2}$. Interestingly, a rigid cyclopalladated 1,10-phenanthroline ligand in the palladacycle $\mathbf{C}$ provided only poor yields of the homoallylic amine (entry 4, Table 1). Comparison of the yields achieved with complexes $\mathbf{A}$ vs. $\mathbf{B}$ and $\mathbf{D}$ vs. E suggests that an increased steric bulk around the heteroatom favors the desired reaction course, possibly due to favoring the $\eta^{1}$ bonding of the allyl fragment to the palladium center in intermediates VI (entries 2, 3, 5 and 6, Fig. 3). No significant differences in the performance of cyclopalladated complexes featuring an $\mathrm{sp}^{2}$-hybridized $\mathrm{N}$-donor (A-F, Fig. 4) and $\mathrm{sp}^{3}$-hybridized $\mathrm{N}$-donor atom (G and H, Fig. 4) were observed. Furthermore, cyclopalladated complexes that differed in the nature of the C-Pd bond, featuring the Pd bonded to either the $\mathrm{sp}^{2}$ - or $\mathrm{sp}^{3}$-hybridized carbons (B and F, Fig. 4) afforded similar yields $61 \%$ and 50\%, respectively, of the homoallylic amine $\mathbf{4 a}$ (entries 3 and 7, Table 1).

Notably, catalysts bearing P-heteroatom and S-heteroatom I-L [11] capable of back-bonding via the d-orbitals and thus diminishing the electron density at the $\mathrm{Pd}(\mathrm{II})$ center in $\eta^{1}$-bonded allylpalladium(II) intermediate VII (Fig. 2) afforded low yields of the amine 4a (entries 1013 , Table 1). The lack of catalytic activity of complex $\mathbf{K}$ is significant in terms of considering the reactive species involved in the catalytic cycle of reactions catalyzed by $\mathrm{Pd}(\mathrm{OAc})_{2} / \mathrm{P}(t-\mathrm{Bu})_{3}$ system, since under the reaction conditions, palladation of the phosphine ligand giving rise to a four-membered cyclopalladated ligand present in the complex $\mathbf{K}$ should be facile [11c].

An attempt to realize asymmetry transfer from chiral nonracemic cyclopalladated complexes $\mathbf{E}, \mathbf{H}$ and $\mathbf{L}$ disappointingly did not afford enantiomerically enriched product $\mathbf{4 a}$ (entries 6,9 and 13, Table 1).

Catalysis with complex A under the optimized conditions (Scheme 1, Table 1) was then employed in the three-component coupling reactions of selected boronic acids 1a-g bearing heteroatom-containing substituents (methoxy, methylcarbonyl, cyano, fluoro, chloro) and the methyl group in the para position. Indeed catalyst $\mathbf{A}$ afforded amines 4a-e bearing methoxy, cyano, fluoro and methylcarbonyl groups in the boronic acid substituents in yields moderately improved (8-34\%) in comparison to the results with the originally reported 
$\mathrm{Pd}(\mathrm{OAc})_{2}$ catalyst, thus extending the scope of the three-component coupling reactions [7]. Some of the boronic acids selected for these experiments afforded particularly low yields of the corresponding amines $\mathbf{4 c}$-e in reactions catalyzed by $\mathrm{Pd}(\mathrm{OAc})_{2} / \mathrm{P}(t-\mathrm{Bu})_{3}$ (entries 5,7 and 9, Table 2). However, substituents that exert relatively the least significant electronic effects on the aromatic ring (e.g. $\mathrm{Me}$ and $\mathrm{Cl}$ ) did not seem to differentiate the performance of the two types of catalysts (compare entries 11 and 12, and 13 and 14, Table 2). Using boronic acids bearing $p$-methyl and $p$-chloro substituents the corresponding amines $\mathbf{4 f}$ and $\mathbf{4 g}$ were obtained in comparable yields using either cyclopalladated catalyst $\mathbf{A}$ or the originally reported $\mathrm{Pd}(\mathrm{OAc})_{2}$ (entries 11-14, Table 2).

To assess the possibility that complex $\mathbf{A}$ serves as a precatalyst ultimately giving rise to intermediates identical to those formed in reactions catalyzed by the $\operatorname{Pd}(\mathrm{OAc})_{2} / \mathrm{P}(t-\mathrm{Bu})_{3}$ system, ${ }^{31} \mathrm{P}$ NMR monitoring experiments were performed. Two reaction mixtures consisting of the boronic acid $\mathbf{1 a}$ ( 2 mol equiv), allene $\mathbf{2}$ ( 5 mol equiv) and imine $\mathbf{3 a}$ ( $1 \mathrm{~mol}$ equiv), $\mathrm{HP}(t-\mathrm{Bu})_{3} \mathrm{PBF}_{4}$ (1 mol equiv), $\mathrm{CsF}$ (4 mol equiv) [12] and either $\mathrm{Pd}(\mathrm{OAc})_{2}(1 \mathrm{~mol}$ equiv) or the cyclopalladated complex A (1 mol equiv) dissolved in THF-d8 were prepared inside NMR tubes at room temperature. For each reaction system, ${ }^{31} \mathrm{P}$ NMR spectra were recorded 16 times over the course of 1 hour (Fig. 5).

After the initial 10 minutes, spectral traces recorded for the reaction mediated by $\mathrm{Pd}(\mathrm{OAc})_{2}$ revealed two signals at $84.8 \mathrm{ppm}$ and at $-9.2 \mathrm{ppm}$, that could be assigned to $\mathrm{Pd}(0) \mathrm{L}_{2}$ complex (84.8 ppm) [13] and to a four-membered cyclometalated P-chelated palladacycle $(-9.2 \mathrm{ppm})$ analogous to the structure of the complex $\mathbf{K}$ (Fig. 4), particularly since and in situ cyclometalation of $\mathrm{P}(t-\mathrm{Bu})_{3}$ ligand is expected to be facile under the reaction conditions [14]. However, since we have shown that complex $\mathbf{K}$ was not an active catalyst for the three-component coupling reaction (entry 12, Table 1), a complex giving rise to the -9.2 ppm ${ }^{31} \mathrm{P}$ NMR signal might represent a stable species formed in a high concentration accompanied by a low concentration of an undetected high-energy catalytically active intermediate [15]. Notably, ${ }^{31} \mathrm{P}$ NMR monitoring of the reaction mediated by the cyclopalladated catalyst A revealed the presence of different intermediates. Thus, a signal for a free $\mathrm{P}(t-\mathrm{Bu})_{3}$ ligand $(63.4 \mathrm{ppm})[16]$, along with a signal at $50.9 \mathrm{ppm}$ that was gradually increasing over 40 minutes time period, were detected (Fig. 5). The signal at 50.9 ppm likely indicates the presence of a $\mathrm{Pd}$ (II) intermediate with a single phosphine ligand present in the coordination sphere along with one more organic ligand, e.g. possibly the proposed intermediates VI or VII (Fig. 3) or their precursors. Although these experiments could not identify the structures of the catalytically active intermediates, the results suggest that distinct catalytic intermediates operate in reactions catalyzed by the cyclopalladated calyst $\mathbf{A}$ in contrast to the reaction catalyzed by $\mathrm{Pd}(\mathrm{OAc})_{2}$, thus underlying the unique catalytic potential and function of the palladacycles in this synthetic process.

In summary, experiments described above yielded the following observations regarding the differences between the reactions catalyzed by $\mathrm{Pd}(\mathrm{OAc})_{2}$ and by the $(\mathrm{C}-\mathrm{N}) \mathrm{Pd}(\mathrm{II})$

palladacycles. Unexpectedly, the presence of an additional phosphine ligand was required to achieve an optimum performance of the (C-N)Pd(II) palladacycles. Best results were obtained with palladacycles featuring nitrogen as the heteroatom in the auxiliary ligand sphere and particularly those possessing an increased steric bulk about the heteroatom (N). As anticipated based on the initial mechanistic proposals (Fig. 2 and Fig. 3), reactions catalyzed by the palladacycles proved to be tolerant of a broader range of substituted boronic acids affording improved yields of functionalized homoallylic amines $\mathbf{4 a - g}$ (Table 2). Finally, distinct intermediates featuring Pd-bonded phosphorus ligands were detected in reactions catalyzed by either the $\mathrm{Pd}(\mathrm{OAc})_{2}$ or the $(\mathrm{C}-\mathrm{N}) \mathrm{Pd}(\mathrm{II})$ palladacycles via ${ }^{31} \mathrm{P}$ NMR monitoring. The chemical shift of the ${ }^{31} \mathrm{P}$ NMR signal detected in the reactions catalyzed by 
$\mathrm{Pd}(\mathrm{OAc})_{2}$ appear to suggest the formation of a cyclometalated complex analogous to the complex K (Fig. 4).

The fact that the cyclopalladated catalyst $\mathbf{A}$ appears to better tolerate substitution with groups significantly effecting the electron density in the aromatic ring of the boronic acid component and consequently a broader range of the rates of B to Pd transmetalation steps, correlates with the fewer number of transmetalation steps needed to assemble the proposed key allylpalladium(II) intermediate VI (paths (a, b) in Fig. 3) bearing the cyclometalated auxiliary ligand than the intermediate $\mathbf{V}$ (path (a) in Fig. 2).

To rationalize the initially unexpected need for additional phoshine ligands in reactions catalyzed by the cyclopalladated catalyst $\mathbf{A}$ it must be considered that the phosphine ligand may play a critical role in one or more of the four phases of the catalytic cycle of the reactions catalyzed by the (C-N)Pd(II) palladacycle A (Fig. 6), including (i) bridge splitting of the original dimer of catalyst $\mathbf{A}$ (path (a) in Fig. 6); (ii) assembly of the allyl fragment via transmetalation and migratory insertion (paths $(a, b)$ in Fig. 6); (iii) equilibrium between the $\eta^{3}$ and $\eta^{1}$-bonded complexes VIa and VIb and VII (path (c) in Fig. 6); (iv) nucleophilic allyl transfer (path (d) in Fig. 6) and finally the (v) catalyst regeneration with concomitant product release (path (e) in Fig. 6). Thus, a revised catalytic cycle for reactions catalyzed by the (C-N) $\mathrm{Pd}$ (II) palladacycle along with the $\mathrm{H}(t-\mathrm{Bu})_{3} \mathrm{PBF}_{4}$ has been proposed (Fig. 6).

In order to understand the role of the phosphine ligand in the bridge splitting of the complex A, control experiments involving ${ }^{31} \mathrm{P}$ NMR monitoring of reaction systems consisting of the cyclopalladated complex $\mathbf{A}$ and $\mathrm{HP}(t-\mathrm{Bu})_{3} \mathrm{BF}_{4}$ along with either $N, N$-diisopropylethyl amine, pyridine or $\mathrm{CsF}$, or both $\mathrm{CsF}$ and $\operatorname{ArB}(\mathrm{OH})_{2}$ were performed. $N, N$-diisopropylethyl amine, pyridine and $\mathrm{CsF}$ are known to release free $\mathrm{P}(t-\mathrm{Bu})_{3}$ from its tetrafluoroborate salt [12]. Evidence for the release of the free phosphine was indeed obtained in the presence of $\mathrm{N}, \mathrm{N}$-diisopropylethyl amine, pyridine and $\mathrm{CsF}$ (for ${ }^{31} \mathrm{P}$ NMR data see the Supporting Information). However, the bridge splitting of complex $\mathbf{A}$ was only detected in the presence of either pyridine or both $\mathrm{CsF}$ and boronic acid $\mathrm{ArB}(\mathrm{OH})_{2}$ and not in the presence of only $\mathrm{CsF}$ and $\mathrm{HP}(t-\mathrm{Bu})_{3} \mathrm{BF}_{4}$ (for ${ }^{31} \mathrm{P} \mathrm{NMR}$ data see Supporting Information). Thus, the phosphine ligand does not play a critical role in the initinal bridge splitting step of the catalytic cycle (Fig. 6).

A component of the reaction mixture, likely the aryl boronic acid ensures the bridgesplitting of complex $\mathbf{A}$, and permits the formation of a complex with the $\mathrm{Pd}(\mathrm{II})$-bonded phosphine (50.9 ppm signal, trace b, Fig. 5).

The formation of an allyl ligand on $\mathrm{Pd}(\mathrm{II})$ centers via migratory insertion of allenes into aryl-Pd(II) bonds (path (b), Fig. 6) both in the presence of absence of auxiliary phosphine lignads has been described in the literature [17, 18], including complexes bearing cyclometalated (C-N) ligands [6b, 18]. Thus, the formation of the allyl palladium(II) intermediate VI via allene migratory insertion is unlikely to constitute the step in which the presence of the phosphine ligand is critical.

However, computational data revealed that in order for the nucleophilic allyl transfer (path (d), Fig. 6) to become feasible, the allyl ligand has to be bonded in the $\eta^{1}$ mode [6d, 9]. These findings are further supported by the facile nucleophilic allyl trasfer from the (PCP)Pd(II) pincer complexes reported by Szabo [6c], in which a single coordination site remains available for the bonding of the allyl fragment. In the absence of a phosphine ligand in the reaction described herein, only weak donor ligands L (allene, imine and THF solvent) are present to shift the position of the equilibrium between the $\eta^{3}$ - and $\eta^{1}$-bonded complexes VIb and VIa and VII in favor of the complex VII that must be formed in order for the 
nucleophilic allyl transfer to occur via a closed transition state, as indicated by the antistereochemistry consistently obtained in the homoallylic amine products.

Thus, the role of the additional phoshine ligand in the reactions catalyzed by complex $\mathbf{A}$ could be rationalized by the involvement of both the phosphine ligand (L) and the imine in a series of ligand exchange equilibriums featuring the allylpalladium(II) intermediates VI and VII, ultimately providing the optimum concentration of the $\eta^{1}$-bonded allylpalladium(II) complex VII necessary for the nucleophilic allyl transfer [6d, 9] (Fig. 6). ${ }^{1}$

Finally, the product release along with catalyst regeneration likely involves transmetalation transferring the aryl group from B to Pd(II) (path (e), Fig. 6). This step must be favored by an electron deficient $\mathrm{Pd}$ (II) center, and therefore the presence of a phosphine donor is not likely to be critical for the release of the homoallylic amine IV.

The ${ }^{31} \mathrm{P}$ NMR monitoring data described in Fig. 5 , trace (a) provide additional insights into the nature of the reactive intermediates involved in the reactions catalyzed by $\mathrm{Pd}(\mathrm{OAc})_{2} /$ $\mathrm{HP}(t-\mathrm{Bu})_{3} \mathrm{BF}_{4}$. The signal detected at $-9.2 \mathrm{ppm}$ suggests that a cyclometalation of the $\mathrm{P}(t-$ $\mathrm{Bu})_{3}$ ligand might be occurring ultimately giving rise to an allylpalladium(II) complex VIII (Fig. 7) [11c]. We observed that an analogous cyclopalladated complex K (Fig. 4) did not prove to be an active catalyst for synthesis of amine $\mathbf{4 a}$ (vide supra). Thus, the in situ cyclopalladation of the phosphine ligand might be diminishing the concentration of the catalytically active $\mathrm{Pd}(\mathrm{II})$ species, and be responsible for the limitations in the performance of the $\mathrm{Pd}(\mathrm{OAc})_{2} / \mathrm{HP}(t-\mathrm{Bu})_{3} \mathrm{BF}_{4}$ catalytic systems discussed herein.

\section{Conclusions}

A new application of pallada(II)cycles featuring a cyclopalladated auxiliary ligand with $\mathrm{N}$ donor atom as catalysts in a three-component coupling reaction for the synthesis of highly substituted homoallylic amines has been described. The optimum pallada(II)cycle afforded improved yields of the homoallylic amines in comparison to the catalytic system based on $\mathrm{Pd}(\mathrm{OAc})_{2}$, in particular in reactions utilizing electronically differentiated boronic acids bearing $\mathrm{MeO}, \mathrm{COOMe}, \mathrm{COMe}, \mathrm{CN}$ and $\mathrm{F}$ substituents. A brief structure-activity survey indicated that the structure of the cyclopalladated auxiliary ligand controlled the catalyst reactivity, and distinct reactive intermediates were detected in the reaction catalyzed by $\mathrm{Pd}(\mathrm{OAc})_{2}$ and the optimum pallada(II)cycle $\mathbf{A}$. The presence of the nitrogen heteroatom and steric bulk in the cyclopalladated ligands were identified as the structural features critical for the optimum reactivity of the palladacyclic catalyst. Furthermore, the need for a phosphine ligand in reactions catalyzed by the pallada(II)cycles was established, and its role in the catalytic cycle of the three-component coupling reaction was proposed. ${ }^{31} \mathrm{P}$ NMR studies provided insights into the structures of the intermediates operating in the reaction catalyzed by $\mathrm{Pd}(\mathrm{OAc})_{2} / \mathrm{HP}(t-\mathrm{Bu})_{3} \mathrm{BF}_{4}$, revealing that an in situ cyclopalladation of the phosphine ligand is likely limiting the performance of the originally reported catalytic system.

\section{Experimental section}

\subsection{General Methods}

Unless otherwise indicated, all NMR data were collected at room temperature in $\mathrm{CDCl}_{3}$ with internal $\mathrm{CHCl}_{3}$ as the reference $\left(\delta 7.26 \mathrm{ppm}\right.$ for ${ }^{1} \mathrm{H}$ and $77.00 \mathrm{ppm}$ for $\left.{ }^{13} \mathrm{C}\right)$ and internal (present in a sealed capillary inserted into the NMR tube) $\mathrm{H}_{3} \mathrm{PO}_{4}(\delta 0 \mathrm{ppm})$ as the reference for ${ }^{31} \mathrm{P}$ NMR. IR spectra were measured as thin films on salt $(\mathrm{NaCl})$ plates. MS were

\footnotetext{
${ }^{1}$ Nucleophilic allyl transfer from an $\eta^{1}$-bonded (PCP)(allyl)Pd(II) pincer complex observed in situ by ${ }^{1} \mathrm{H}$ NMR to aldehydes and imines was examined by DFT calculations, see [6d] and references cited therein.
} 
measured under electrospray ionization (ES+) conditions. HPLC was recorded with Shimadzu SCL-10A system equipped with CHIRALCEL OD column. Analytical thin-layer chromatography (TLC) was carried out on commercial Merck silica gel 60 plates, $0.25 \mu \mathrm{m}$ thickness, with fluorescent indicator (F-254) or stained with aqueous $\mathrm{KMnO}_{4}$ solution. Column chromatography was performed with 40-63 $\mu \mathrm{m}$ silica gel (Sorbent).

Tetrahydrofuran (THF) was freshly distilled from sodium/benzophenone. Methylene chloride, toluene, acetonitrile, and DMF were kept over $3 \AA$ ( $8-12$ mesh) molecular sieves. Benzene was distilled from $\mathrm{CaH}_{2}$ and kept over $3 \AA$ ( $8-12$ mesh) molecular sieves under an atmosphere of dry argon; other solvents were used as received. Unless otherwise specified, all reactions were carried out under an atmosphere of dry argon in oven-dried (at least $6 \mathrm{~h}$ at $140{ }^{\circ} \mathrm{C}$ ) glassware. $p$-Methoxyphenylboronic acid and $p$-chlorophenylboronic acid were purchased from Sigma-Aldrich, purified by recrystallization from water, and dried under vacuum for at least 16 h. 1,2-nonadiene [19] and (E)-N-benzylidene-4-methoxyaniline [20] were prepared according to modified literature procedures. Pd complexes A-L [10,11] were prepared according to indicated literature procedure. Other materials were used as received from commercial suppliers.

\subsection{General protocol for the preparation of homoallylic amines}

Homoallylic amines were prepared according to a modified literature procedure [7a]. A solution of 1,2-nonadiene 2 ( $1.25 \mathrm{mmol}, 5.0$ equiv) in dry THF ( $3.0 \mathrm{ml}$ ) was injected into a vessel containing the solid reagents including (E)-N-benzylidene-4-methoxyaniline 3a $(0.25$ mmol 1.0 equiv), boronic acid 1a-g $(0.50 \mathrm{mmol}, 2.0$ equiv), palladium acetate $(0.025 \mathrm{mmol}$, 0.1 equiv) or palladium complex A-L ( $0.0125 \mathrm{~mol}, 0.05$ equiv), phosphine ligand, tri-tbutylphosphonium tetrafluoroborate, triphenylphosphine, or tri-o-tolylphosphine $(0.025$ mmol, 0.10 equiv) and $\mathrm{CsF}$ (1.00 mmol, 4.0 equiv). The reaction mixture was then stirred at $40{ }^{\circ} \mathrm{C}$ under argon for $24 \mathrm{~h}$. Water $(20 \mathrm{ml})$ was added, and the mixture was extracted with ether $(4 \times 20 \mathrm{ml})$. Organic extracts were dried $\left(\mathrm{MgSO}_{4}\right)$, and the solvents were removed under reduced pressure to afford the crude products that were separated by flash chromatography over silica eluting with EtOAc/Hexanes mixtures to yield pure amines as yellow oils.

\subsection{Application of the general protocol to the experiments described in Scheme 1}

The following protocol was applied to experiments described in Scheme 1. Treatment of 1,2-nonadiene 2 ( $0.155 \mathrm{~g}, 1.25 \mathrm{mmol}, 5.0$ equiv), (E)-N-benzylidene-4-methoxyaniline 3a (0.053 g, 0.25 mmol 1.0 equiv), p-methoxycarbonylphenylboronic acid $1 \mathbf{a}(0.090 \mathrm{~g}, 0.50$ mmol, 2.0 equiv), either palladium acetate $(0.006 \mathrm{~g}, 0.025 \mathrm{mmol}, 0.1$ equiv) or palladium complex A ( $0.009 \mathrm{~g}, 0.0125 \mathrm{~mol}, 0.05$ equiv), and one of the following phosphine ligands, tri-t-butylphosphonium tetrafluoroborate $(0.0073 \mathrm{~g}, 0.025 \mathrm{mmol}, 0.10$ equiv), triphenyl phosphine $(0.0066 \mathrm{~g}, 0.025 \mathrm{mmol}, 0.10$ equiv), tri-o-tolylphosphine $(0.0076 \mathrm{~g}, 0.025 \mathrm{mmol}$, 0.10 equiv), or phenyl-(di-t-butyl)phosphonium tetrafluoroborate $(0.0078 \mathrm{~g}, 0.025 \mathrm{mmol}$, 0.10 equiv), and $\mathrm{CsF}(0.151 \mathrm{~g}, 1.00 \mathrm{mmol}, 4.0$ equiv) according to the general procedure described above followed by flash chromatography over silica eluting with EtOAc/Hexanes (1:20) afforded $\mathbf{4 a}$ as a yellow oil.

\subsection{Application of the general protocol to the experiments described in Table 1}

The following protocol was applied to experiments described in Table 1 . Treatment of a series of palladium complexes A-L ( $0.012 \mathrm{mmol}, 0.10$ equiv of Pd), 1,2-nonadiene 2 ( 0.155 g, $1.25 \mathrm{mmol}$, 5.0 equiv), (E)-N-benzylidene-4-methoxyaniline 3a ( $0.053 \mathrm{~g}, 0.25 \mathrm{mmol} 1.0$ equiv), $p$-methoxycarbonylphenylboronic acid $1 \mathbf{a}(0.090 \mathrm{~g}, 0.50 \mathrm{mmol}, 2.0$ equiv), tri-tbutylphosphonium tetrafluoroborate $(0.0073 \mathrm{~g}, 0.025 \mathrm{mmol}, 0.10$ equiv), and CsF $(0.151 \mathrm{~g}$, $1.00 \mathrm{mmol}, 4.0$ equiv) according to the general procedure described above followed by flash 
chromatography over silica eluting with EtOAc/Hexanes (1:20) afforded $\mathbf{4 a}$ as a yellow oil. The amounts of palladium complexes used were as following:

Catalyst A (9.4 mg) afforded amine $\mathbf{4 a}(90 \mathrm{mg}, 76 \%)$

Catalyst B (8.0 mg) afforded amine $\mathbf{4 a}(72 \mathrm{mg}, 61 \%)$

Catalyst C (8.6 mg) afforded amine $\mathbf{4 a}(25 \mathrm{mg}, 21 \%)$

Catalyst $\mathbf{D}(7.8 \mathrm{mg})$ afforded amine $\mathbf{4 a}(65 \mathrm{mg}, 55 \%)$

Catalyst E (8.8 mg) afforded amine $\mathbf{4 a}(79 \mathrm{mg}, 67 \%, 3.1 \%$ ee)

Catalyst $\mathbf{F}(7.7 \mathrm{mg})$ afforded amine $\mathbf{4 a}(59 \mathrm{mg}, 50 \%)$

Catalyst $\mathbf{G}(8.1 \mathrm{mg})$ afforded amine $\mathbf{4 a}(68 \mathrm{mg}, 58 \%)$

Catalyst $\mathbf{H}(7.8 \mathrm{mg})$ afforded amine $\mathbf{4 a}(66 \mathrm{mg}, 56 \%, 2.0 \%$ ee)

Catalyst I (11.0 mg) afforded amine $\mathbf{4 a}(40 \mathrm{mg}, 34 \%)$

Catalyst $\mathbf{J}(11.8 \mathrm{mg})$ afforded amine $\mathbf{4 a}(19 \mathrm{mg}, 16 \%)$

Catalyst K $(8.0 \mathrm{mg})$ afforded amine $\mathbf{4 a}(34 \mathrm{mg}, 29 \%)$

Catalyst L (9.0 mg) afforded amine $\mathbf{4 a}$ (24 mg, $20 \%$, no significant \% ee observed)

HPLC was recorded with Shimadzu SCL-10A system equipped with CHIRALCEL OD column, eluting with $1 \%$ isopropanol in hexane.

\subsection{Preparation and complete characterization of homoallylic amines $4 \mathrm{a}-\mathrm{g}$ (Table 2)}

4.5.1 General protocol-Homoallylic amines were prepared according to the general protocol described in section 4.2.

\subsection{N-p-methoxyphenyl-2-(1-hexyl)-3-(p-methoxycarbonylphenyl)-1-} (phenyl)-3-butenamine (4a)-Treatment of $p$-methoxycarbonylphenylboronic acid 1a $(0.090 \mathrm{~g}, 0.50 \mathrm{mmol}, 2.0$ equiv) according to the general procedure described above followed by flash chromatography over silica eluting with EtOAc/Hexanes (1:20) afforded 4a $\left(0.072 \mathrm{~g}, 61 \%\right.$ with $\mathrm{Pd}(\mathrm{OAc})_{2}$ and $0.090 \mathrm{~g}, 76 \%$ with $\left.\mathbf{A}\right)$ as a yellow oil.

Analytical data for 4a: $\mathrm{R}_{f}=0.22($ EtOAc/Hexane $=1 / 10) ;{ }^{1} \mathrm{H}$ NMR $(400 \mathrm{MHz}) \delta 7.93(\mathrm{~d}, J$ $=8.0 \mathrm{~Hz}, 2 \mathrm{H}), 7.31-7.16(\mathrm{~m}, 7 \mathrm{H}), 6.61(\mathrm{~d}, J=12.0 \mathrm{~Hz}, 2 \mathrm{H}), 6.39(\mathrm{~d}, J=12.0 \mathrm{~Hz}, 2 \mathrm{H})$, $5.43(\mathrm{~s}, 1 \mathrm{H}), 5.29(\mathrm{~s}, 1 \mathrm{H}), 4.14(\mathrm{~s} \mathrm{br}, 1 \mathrm{H}), 4.07(\mathrm{~d}, J=8.0 \mathrm{~Hz}, 1 \mathrm{H}), 3.92(\mathrm{~s}, 3 \mathrm{H}), 3.67(\mathrm{~s}$, $3 \mathrm{H}), 2.80(\mathrm{q}, J=8.0 \mathrm{~Hz}, 1 \mathrm{H}), 1.33-1.11(\mathrm{~m}, 10 \mathrm{H}), 0.82(\mathrm{t}, J=8.0 \mathrm{~Hz}, 3 \mathrm{H}) ;{ }^{13} \mathrm{C} \mathrm{NMR}$ (125 MHz) $\delta 166.9,151.9,149.6,147.1,147.0,145.1,142.8,141.5,129.6$ (2 carbons), 129.0, 128.3 ( 2 carbons), 127.6 ( 2 carbons), 127.3 ( 2 carbons), 127.1, 117.6, 114.7 (2 carbons), 114.6 (2 carbons), 62.1, 55.7, 53.2, 52.1, 31.7, 30.3, 29.2, 27.4, 22.6, 14.1; IR (neat, $\mathrm{cm}^{-1}$ ) $3402\left(\mathrm{w}\right.$ br), $1718(\mathrm{~s}), 1607(\mathrm{~m})$; HRMS $\left(\mathrm{ES}^{+}\right) \mathrm{C}_{31} \mathrm{H}_{38} \mathrm{NO}_{3}$, calcd $\mathrm{M}+\mathrm{H}^{+}=$ 472.2852, found 472.2821 .

\subsubsection{N-p-methoxyphenyl-2-(1-hexyl)-3-(p-methoxyphenyl)-1-(phenyl)-3-} butenamine (4b)-Treatment of $p$-methoxyphenylboronic acid $\mathbf{1 b}(0.076 \mathrm{~g}, 0.50 \mathrm{mmol}$, 2.0 equiv) according to the general procedure described above followed by flash chromatography over silica eluting with EtOAc/Hexanes (1:30) afforded $\mathbf{4 b}(0.053 \mathrm{~g}, 48 \%$ with $\mathrm{Pd}(\mathrm{OAc})_{2}$ and $0.071 \mathrm{~g}, 64 \%$ with $\left.\mathbf{A}\right)$ as a yellow oil.

Analytical data for $4 \mathbf{b}: \mathrm{R}_{f}=0.20($ EtOAc/Hexane $=1 / 20) ;{ }^{1} \mathrm{H}$ NMR $(400 \mathrm{MHz}) \delta 7.34(\mathrm{~d}, J$ $=4.0 \mathrm{~Hz}, 2 \mathrm{H}), 7.28-7.24(\mathrm{~m}, 3 \mathrm{H}), 7.20(\mathrm{~d}, J=8.0 \mathrm{~Hz}, 2 \mathrm{H}), 6.84(\mathrm{~d}, J=8.0 \mathrm{~Hz}, 2 \mathrm{H}), 6.61$ $(\mathrm{d}, J=8.0 \mathrm{~Hz}, 2 \mathrm{H}), 6.38(\mathrm{~d}, J=8.0 \mathrm{~Hz}, 2 \mathrm{H}), 5.32(\mathrm{~s}, 1 \mathrm{H}), 5.16(\mathrm{~s}, 1 \mathrm{H}), 4.06(\mathrm{~d}, J=12.0$ 
$\mathrm{Hz}, 1 \mathrm{H}), 3.81$ (s, $3 \mathrm{H}), 3.66$ (s, $3 \mathrm{H}), 2.72(\mathrm{q}, J=8.0 \mathrm{~Hz}, 1 \mathrm{H}), 1.28-1.10(\mathrm{~m}, 10 \mathrm{H}), 0.81$ (t, $J=8.0 \mathrm{~Hz}, 3 \mathrm{H}) ;{ }^{13} \mathrm{C}$ NMR $(125 \mathrm{MHz}) \delta 159.0,151.8,149.59,143.3,141.8,134.59,128.3$ (2 carbons), 128.2 (2 carbons), 127.7 (2 carbons), 127.0, 115.5, 114.6 (2 carbons), 114.5 (2 carbons), 113.7 (2 carbons), 62.5, 55.7, 55.3, 31.66, 30.57, 29.2, 27.3, 22.6, 14.1; IR 3398 (w br), 1510 (s), 1242 (s); HRMS (ES ${ }^{+}$) $\mathrm{C}_{30} \mathrm{H}_{38} \mathrm{NO}_{2}$, calcd $\mathrm{M}+\mathrm{H}^{+}=444.2903$, found 444.2896 .

4.5.4 N-p-methoxyphenyl-2-(1-hexyl)-3-(p-acetylphenyl)-1-(phenyl)-3butenamine (4c)-Treatment of $p$-acetylphenylboronic acid $1 \mathrm{c}(0.082 \mathrm{~g}, 0.50 \mathrm{mmol}, 2.0$ equiv) according to the general procedure described above followed by flash chromatography over silica eluting with EtOAc/Hexanes (1:30) afforded $4 \mathbf{c}(0.049 \mathrm{~g}, 43 \%$ with $\mathrm{Pd}(\mathrm{OAc})_{2}$ and $0.088 \mathrm{~g}, 77 \%$ with $\left.\mathbf{A}\right)$ as a yellow oil.

Analytical data for 4c: $\mathrm{R}_{f}=0.26($ EtOAc/Hexane $=1 / 8) ;{ }^{1} \mathrm{H}$ NMR $(400 \mathrm{MHz}) \delta 7.88(\mathrm{~d}, J=$ $8.0 \mathrm{~Hz}, 2 \mathrm{H}), 7.35(\mathrm{~d}, J=8.0 \mathrm{~Hz}, 2 \mathrm{H}), 7.30-7.28(\mathrm{~m}, 4 \mathrm{H}), 7.21(\mathrm{t}, J=8.0 \mathrm{~Hz}, 1 \mathrm{H}), 6.65(\mathrm{~d}$, $J=8.0 \mathrm{~Hz}, 2 \mathrm{H}), 6.41(\mathrm{~d}, J=8.0 \mathrm{~Hz}, 2 \mathrm{H}), 5.47(\mathrm{~s}, 1 \mathrm{H}), 5.34(\mathrm{~s}, 1 \mathrm{H}), 4.17(\mathrm{~s} \mathrm{br}, 1 \mathrm{H}), 4.10$ (d, $J=8.0 \mathrm{~Hz}, 1 \mathrm{H}), 3.69$ (s, $3 \mathrm{H}), 2.84(\mathrm{q}, J=8.0 \mathrm{~Hz}, 1 \mathrm{H}), 2.62(\mathrm{~s}, 3 \mathrm{H}), 1.37-1.15$ (m, 10 $\mathrm{H}), 0.83(\mathrm{t}, J=8.0 \mathrm{~Hz}, 3 \mathrm{H}) ;{ }^{13} \mathrm{C}$ NMR $(125 \mathrm{MHz}) \delta 197.8,151.9,149.5,147.1,142.8$, 141.5, 128.4 ( 2 carbons), 128.3 ( 2 carbons), 127.6 ( 2 carbons), 127.5 ( 2 carbons), 127.1 ( 2 carbons), 117.7, 114.7, 114.6, 62.1, 55.7, 53.2, 31.7, 30.3, 29.2, 27.4, 26.6, 22.6, 14.1; IR (neat, $\mathrm{cm}^{-1}$ ) $3398\left(\mathrm{w}\right.$ br), $1682(\mathrm{~m}), 1602(\mathrm{~m})$; HRMS $\left(\mathrm{ES}^{+}\right) \mathrm{C}_{31} \mathrm{H}_{38} \mathrm{NO}_{2}$, calcd $\mathrm{M}+\mathrm{H}^{+}=$ 456.2903, found 456.2875.

\subsubsection{N-p-methoxyphenyl-2-(1-hexyl)-3-(p-cyanophenyl)-1-(phenyl)-3-}

butenamine (4d)-Treatment of $p$-cyanophenylboronic acid $\mathbf{1 d}(0.074 \mathrm{~g}, 0.50 \mathrm{mmol}, 2.0$ equiv) according to the general procedure described above followed by flash chromatography over silica eluting with EtOAc/Hexanes (1:30) afforded 4d $(0.034 \mathrm{~g}, 30 \%$ with $\mathrm{Pd}(\mathrm{OAc})_{2}$ and $0.062 \mathrm{~g}, 54 \%$ with $\left.\mathbf{A}\right)$ as a yellow oil.

Analytical data for 4d: $\mathrm{R}_{f}=0.20($ EtOAc/Hexane $=1 / 10) ;{ }^{1} \mathrm{H}$ NMR $(400 \mathrm{MHz}) \delta 7.52(\mathrm{~d}, J$ $=8.0 \mathrm{~Hz}, 2 \mathrm{H}), 7.29(\mathrm{~d}, J=8.0 \mathrm{~Hz}, 2 \mathrm{H}), 7.24-7.21(\mathrm{~m}, 3 \mathrm{H}), 7.16(\mathrm{~d}, J=8.0 \mathrm{~Hz}, 2 \mathrm{H}), 6.63$ $(\mathrm{d}, J=8.0 \mathrm{~Hz}, 2 \mathrm{H}), 6.37$ (d, $J=12.0 \mathrm{~Hz}, 2 \mathrm{H}), 5.43(\mathrm{~s}, 1 \mathrm{H}), 5.34(\mathrm{~s}, 1 \mathrm{H}), 4.09$ (d, $J=8.0$ $\mathrm{Hz}, 1 \mathrm{H}), 4.07$ (s br. $1 \mathrm{H}), 3.67$ (s, $3 \mathrm{H}), 2.83$ (q, $J=8.0 \mathrm{~Hz}, 1 \mathrm{H}), 1.37-1.15(\mathrm{~m}, 10 \mathrm{H}), 0.83$ $(\mathrm{t}, J=8.0 \mathrm{~Hz}, 3 \mathrm{H}) ;{ }^{13} \mathrm{C}$ NMR $(125 \mathrm{MHz}) \delta 152.0,149.0,158.5,147.1,142.1,141.2,132.0$ ( 2 carbons), 128.3 ( 2 carbons), 127.9 ( 2 carbons), 127.5 ( 2 carbons), 127.2, 118.9, 118.3, 114.7 ( 2 carbons), 114.6 ( 2 carbons), 110.9, 61.6, 55.7, 53.0, 31.6, 30.8, 28.9, 27.4, 22.6, 14.1; IR (neat, cm ${ }^{-1}$ ) 3402 (w br), 2225 (m), 1512 (s), 1238 (s); HRMS (ES ${ }^{+}$) $\mathrm{C}_{30} \mathrm{H}_{35} \mathrm{~N}_{2} \mathrm{O}$, calcd $\mathrm{M}+\mathrm{H}^{+}=439.2749$, found 439.2740 .

\subsubsection{N-p-methoxyphenyl-2-(1-hexyl)-3-(p-fluorophenyl)-1-(phenyl)-3-}

butenamine (4e)-Treatment of $p$-fluorophenylboronic acid $1 \mathrm{e}(0.070 \mathrm{~g}, 0.50 \mathrm{mmol}, 2.0$ equiv) according to the general procedure described above followed by flash chromatography over silica eluting with EtOAc/Hexanes (1:40) afforded 4e $(0.031 \mathrm{~g}, 29 \%$ with $\mathrm{Pd}(\mathrm{OAc})_{2}$ and $0.040 \mathrm{~g}, 37 \%$ with $\left.\mathbf{A}\right)$ as a yellow oil.

Analytical data for 4e: $\mathrm{R}_{f}=0.29(\mathrm{EtOAc} / \mathrm{Hexane}=1 / 20) ;{ }^{1} \mathrm{H}$ NMR $(400 \mathrm{MHz}) \delta 7.31(\mathrm{~d}, J$ $=4.0 \mathrm{~Hz}, 2 \mathrm{H}), 7.26(\mathrm{~d}, J=8.0 \mathrm{~Hz}, 2 \mathrm{H}), 7.21-7.17(\mathrm{~m}, 3 \mathrm{H}), 6.96(\mathrm{t}, J=8.0 \mathrm{~Hz}, 2 \mathrm{H}), 6.61$ $(\mathrm{d}, J=12.0 \mathrm{~Hz}, 2 \mathrm{H}), 6.39$ (d, $J=12.0 \mathrm{~Hz}, 2 \mathrm{H}), 5.33(\mathrm{~s}, 1 \mathrm{H}), 5.22(\mathrm{~s}, 1 \mathrm{H}), 4.18$ (s br. $1 \mathrm{H}$ ), $4.03(\mathrm{~d}, J=8.0 \mathrm{~Hz}, 1 \mathrm{H}), 3.67$ (s, $3 \mathrm{H}), 2.73(\mathrm{q}, J=8.0 \mathrm{~Hz}, 1 \mathrm{H}), 1.29-1.11(\mathrm{~m}, 10 \mathrm{H}), 0.82$ $(\mathrm{t}, J=8.0 \mathrm{~Hz}, 3 \mathrm{H}) ;{ }^{13} \mathrm{C}$ NMR $(125 \mathrm{MHz}) \delta 162.7\left(\mathrm{~d}, J_{13 \mathrm{C}-19 \mathrm{~F}}=245 \mathrm{~Hz}\right), 151.9,149.3$, 143.0, 141.6, 138.1, 129.0, 128.9, 128.3 (2 carbons), 127.7 ( 2 carbons), 127.0, 116.8, 115.2, 115.0, 114.7 (2 carbons), 114.5 ( 2 carbons), 62.0, 55.7, 53.6, 31.7, 30.5, 29.2, 27.4, 22.6, 
14.1; IR(neat, $\left.\mathrm{cm}^{-1}\right) 3404$ (w br), 1510 (s), 1238 (s); HRMS (ES ${ }^{+}$) $\mathrm{C}_{29} \mathrm{H}_{35} \mathrm{FNO}$, calcd M + $\mathrm{H}^{+}=432.2703$, found 432.2697 .

\subsection{N-p-methoxyphenyl-2-(1-hexyl)-3-(p-chlorophenyl)-1-(phenyl)-3-}

butenamine (4f)-Treatment of $p$-chlorophenylboronic acid $\mathbf{1 f}(0.078 \mathrm{~g}, 0.50 \mathrm{mmol}, 2.0$ equiv) according to the general procedure described above followed by flash chromatography over silica eluting with EtOAc/Hexanes (1:40) afforded $\mathbf{4 f}(0.061 \mathrm{~g}, 54 \%$ with $\mathrm{Pd}(\mathrm{OAc})_{2}$ and $0.063 \mathrm{~g}, 56 \%$ with $\left.\mathbf{A}\right)$ as a yellow oil.

Analytical data for 4f: $\mathrm{R}_{f}=0.30($ EtOAc/Hexane $=1 / 20) ;{ }^{1} \mathrm{H}$ NMR $(400 \mathrm{MHz}) \delta 7.34-7.27$ $(\mathrm{m}, J=4.0 \mathrm{~Hz}, 5 \mathrm{H}), 7.23(\mathrm{~d}, J=4.0 \mathrm{~Hz}, 2 \mathrm{H}), 7.20(\mathrm{~d}, J=8.0 \mathrm{~Hz}, 2 \mathrm{H}), 6.65(\mathrm{~d}, J=8.0 \mathrm{~Hz}$, $2 \mathrm{H}), 6.40(\mathrm{~d}, J=8.0 \mathrm{~Hz}, 2 \mathrm{H}), 5.38(\mathrm{~s}, 1 \mathrm{H}), 5.26(\mathrm{~s}, 1 \mathrm{H}), 4.18(\mathrm{~s}$ br. $1 \mathrm{H}), 4.06(\mathrm{~d}, J=8.0$ $\mathrm{Hz}, 1 \mathrm{H}), 3.69$ (s, $3 \mathrm{H}), 2.76$ (q, $J=8.0 \mathrm{~Hz}, 1 \mathrm{H}), 1.33-1.14(\mathrm{~m}, 10 \mathrm{H}), 0.85$ (t, $J=8.0 \mathrm{~Hz}, 3$ $\mathrm{H}) ;{ }^{13} \mathrm{C}$ NMR (125 MHz) $\delta 151.9,149.2,142.9,141.5,140.5,133.2,128.7$ (2 carbons), 128.4 ( 2 carbons), 128.3 ( 2 carbons), 127.6 ( 2 carbons), 127.0, 117.0, 114.7 ( 2 carbons), 114.6 ( 2 carbons), 62.0, 55.7, 53.5, 31.7, 30.0, 29.0, 27.7, 22.6, 14.1; IR (neat, $\mathrm{cm}^{-1}$ ) 3404 (w br), 1510 (s), 1238 (s) ; HRMS (ES ${ }^{+} \mathrm{C}_{29} \mathrm{H}_{35} \mathrm{ClNO}$, calcd $\mathrm{M}+\mathrm{H}^{+}=448.2407$, found 448.2386 .

\subsubsection{N-p-methoxyphenyl-2-(1-hexyl)-3-(p-tolyl)-1-(phenyl)-3-butenamine (4g)-} Treatment of $p$-tolylboronic acid $1 \mathrm{~g}(0.068 \mathrm{~g}, 0.50 \mathrm{mmol}, 2.0$ equiv $)$ according to the general procedure described above followed by flash chromatography over silica eluting with EtOAc/Hexanes (1:40) afforded $4 \mathrm{~g}\left(0.060 \mathrm{~g}, 56 \%\right.$ with $\mathrm{Pd}(\mathrm{OAc})_{2}$ and $0.062 \mathrm{~g}, 58 \%$ with A) as a yellow oil.

Analytical data for 4g: $\mathrm{R}_{f}=0.28($ EtOAc/Hexane $=1 / 20) ;{ }^{1} \mathrm{H}$ NMR $(400 \mathrm{MHz}) \delta 7.38(\mathrm{~d}, J$ $=8.0 \mathrm{~Hz}, 2 \mathrm{H}), 7.29(\mathrm{t}, J=8.0 \mathrm{~Hz}, 2 \mathrm{H}), 7.21(\mathrm{t}, J=8.0 \mathrm{~Hz}, 1 \mathrm{H}), 7.18(\mathrm{~d}, J=8.0 \mathrm{~Hz}, 2 \mathrm{H})$, $7.13(\mathrm{~d}, J=8.0 \mathrm{~Hz}, 2 \mathrm{H}), 6.62(\mathrm{~d}, J=8.0 \mathrm{~Hz}, 2 \mathrm{H}), 6.38(\mathrm{~d}, J=8.0 \mathrm{~Hz}, 2 \mathrm{H}), 5.37(\mathrm{~s}, 1 \mathrm{H})$, $5.19(\mathrm{~s}, 1 \mathrm{H}), 4.23(\mathrm{~s}$ br. $1 \mathrm{H}), 4.05(\mathrm{~d}, J=8.0 \mathrm{~Hz}, 2 \mathrm{H}), 3.67(\mathrm{~s}, 3 \mathrm{H}), 2.75(\mathrm{q}, J=4.0 \mathrm{~Hz}, 1$ $\mathrm{H}), 2.36(\mathrm{~s}, 3 \mathrm{H}), 1.32-1.11(\mathrm{~m}, 10 \mathrm{H}), 0.83(\mathrm{t}, J=8.0 \mathrm{~Hz}, 3 \mathrm{H}) ;{ }^{13} \mathrm{C} \mathrm{NMR}(125 \mathrm{MHz}) \delta$ $151.8,150.1,143.4,141.9,139.3,137.12,129.0$ ( 2 carbons), 128.3 ( 2 carbons), 127.8 ( 2 carbons), 127.2 ( 2 carbons), 127.0, 116.0, 114.6 ( 2 carbons), 114.5 ( 2 carbons), 62.6, 55.7, 53.5, 31.7, 30.5, 29.2, 27.3, 22.6, 21.1, 14.1; IR (neat, $\mathrm{cm}^{-1}$ ) 3400 (w br), 1510 (s), 1238 (s); HRMS $\left(\mathrm{ES}^{+}\right) \mathrm{C}_{30} \mathrm{H}_{38} \mathrm{NO}$, calcd $\mathrm{M}+\mathrm{H}^{+}=428.2953$, found 428.2916 .

\section{Supplementary Material}

Refer to Web version on PubMed Central for supplementary material.

\section{Acknowledgments}

This work was supported in part by the Office of Science of the U.S. Department of Energy (DEFG02-06ER15792) and the National Institutes of Health Kansas University Chemical Methodologies and Library Development Center of Excellence (NIH0063950 P50).

\section{References}

1. (a) Cope AC, Siekman RW. Formation of covalent bonds from Platinum or Palladium to carbon by direct substitution. J. Am. Chem. Soc. 1965; 87:3272-3273.(b) Cope AC, Friedrich EC. Electrophilic aromatic substitution reactions by Platinum(II) and Palladium(II) chlorides on $N, N$ dimethylbenzylamines. J. Am. Chem. Soc. 1968; 90:909-913.

2. (a) Chartoire A, Lesieur M, Slawin AMZ, Nolan SP, Cazin CSJ. Highly active well-defined Palladium precatalyst for the efficient amination of aryl chlorides. Organometallics. 2011; 30:44324436.(b) Zim D, Buchwald SL. An air and thermally stable one-component catalyst for the 
amination of aryl chlorides. Org. Lett. 2003; 5:2413-2415. [PubMed: 12841743] (c) Dupont J, Consorti CS, Spencer J. Potential of palladacycles: more than just precatalysts. Chem. Rev. 2005; 105:2527-2571. [PubMed: 15941221]

3. (a) Beletskaya IP, Cheprakov AV. Palladacycles in catalysis-a critical survey. J. Organomet. Chem. 2004; 689:4055-4082.(b) Louie J, Hartwig JF. A Route to $\mathrm{Pd}^{0}$ from $\mathrm{Pd}^{\mathrm{II}}$ metallacycles in amination and cross-coupling chemistry. Angew. Chem. Int. Ed. Engl. 1996; 35:2359-2361.(c) Farina V. High-Turnover Palladium Catalysts in Cross-Coupling and Heck Chemistry: A Critical Overview. Adv. Synth. Catal. 2004; 346:1553-1582.

4. (a) Shaw BL. Speculations on new mechanisms for Heck reactions. New J. Chem. 1998; 22:77-79. (b) Shaw BL, Perera SD, Staley EA. Highly active, stable catalysts for the Heck reaction; further suggestions on the mechanism. Chem. Commun. 1998:1361-1362.

5. (a) Neufeldt SR, Sanford MS. O-Acetyl oximes as transformable directing groups for Pd-catalyzed C-H bond functionalization. Org. Lett. 2010; 12:532-535. [PubMed: 20041702] (b) Dick AR, Hull KL, Sanford MS. A highly selective catalytic method for the oxidative functionalization of C-H bonds. J. Org. Chem. 2004; 126:2300-2230.

6. (a) Anderson CE, Overman LE. Catalytic asymmetric rearrangement of allylic trichloroacetimidates. A practical method for preparing allylic amines and congeners of high enantiomeric purity. J. Am. Chem. Soc. 2003; 125:12412-12413. [PubMed: 14531676] (b) Gai X, Grigg R, Collard S, Muir JE. Palladium catalyzed intramolecular nucleophilic addition of allylic species, generated from allene, to aryl aldehydes and ketones. Chem. Commun. 2000:1765-1766.(c) Solin N, Wallner OA, Szabo KJ. Palladium Pincer-Complex Catalyzed Allylation of Tosylimines by Potassium Trifluoro(allyl)borates. Org. Lett. 2005; 7:689-691. [PubMed: 15704926] (d) Selander N, Szabo KJ. Catalysis by Palladium pincer complexes. Chem. Rev. 2011; 111:2048-2076. [PubMed: 21087012]

7. (a) Hopkins CD, Malinakova HC. Allylpalladium umpolung in the three-component coupling synthesis of homoallylic amines. Org. Lett. 2006; 8:5971-5974. [PubMed: 17165907] (b) Hopkins $\mathrm{CD}$, Malinakova HC. Synthesis of unnatural alpha-amino acid derivatives via a three-component coupling method utilizing an allylpalladium umpolung. Synthesis. 2007; 22:3558-3566.

8. (a) Nakamura H, Iwama H, Yamamoto Y. Palladium- and Platinum-catalyzed addition of aldehydes and imines with allylstannanes. Chemoselective allylation of imines in the presence of aldehyde. J. Am. Chem. Soc. 1996; 118:6641-6647.(b) Sebelius S, Wallner OA, Szabo KJ. Palladium-catalyzed coupling of allyl acetates with aldehyde and imine electrophiles in the presence of bis(pinacolato)diboron. Org. Lett. 2003; 5:3065-3068. [PubMed: 12916982] (c) Kurosawa H,

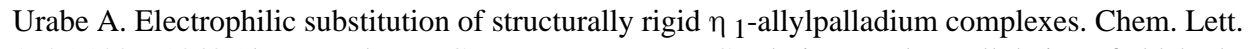
1985:1839-1840.(d) Barczak NR, Grote RE, Jarvo ER. Catalytic umpolung allylation of aldehydes by $\pi$-allylpalladium complexes containing bidentate $\mathrm{N}$-heterocyclic carbene ligands. Organometallics. 2007; 26:4863-4865.

9. Szabo KJ. Palladium-Catalyzed Electrophilic Allylation Reactions via Bis(allyl)palladium Complexes and Related Intermediates. Chem. Eur. J. 2004; 10:5268-5275. [PubMed: 15372656]

10. For the synthesis of complex A, see: Navarro-Ranninger C, Zamora F, Martinez-Cruz LA, Isea R, Masaguer JR. Synthesis and NMR structural analysis of several orthopalladated complexes of substituted benzo-imidazole, -oxazole, and -thiazole and study two polymorphic crystals. J. Organomet. Chem. 1996; 518:29-36. For the synthesis of complexes B and C, see: (b) "Synthesis and characterization of a homologous series of mononuclear palladium complexes containing different cyclometalated ligands" Aiello I, Crispini A, Ghedini M, La Deda M, Barigelletti F. Inorg. Chim. Acta. 2000; 308:121-128. For the synthesis of complex D, see: (c) Ohff M, Ohff A, Milstein D. Highly active Pd(II) cyclometallated imine catalysts for the Heck reaction. Chem. Commun. 1999:357-358. For the synthesis of complex E, see: (d) Hallman K, Moberg C. Palladium(II)-catalyzed oxidation of alcohols with air as reoxidant. Adv. Synth. Catal. 2001; 343:260-263. For the synthesis of complex F, see: (e) Evans P, Hogg P, Grigg R, Nurnabi M, Hinsley J, Sridharan V, Suganthan S, Korn S, Simon C, Muir JE. 8-Methylquinoline palladacycles: stable and efficient catalysts for carbon-carbon bond formation. Tetrahedron. 2005; 61:9696-9704. For the synthesis of complex G, see: (d) Thompson JM, Heck RF. Carbonylation reactions of ortho-palladation products of a-arylnitrogen derivatives. J. Org. Chem. 1975; 40:2667-2674. For the synthesis of complex H, see: (e) Mosteiro R, Fernandez A, VazquezGarcia D, Lopez-Torres M, Rodriguez-Castro A, Gomez-Blanco N, Vila JM, Fernandez JJ. 
Cyclometallated palladium diphosphane compounds derived from the chiral ligands $(S)$ $\mathrm{PhCH}(\mathrm{Me}) \mathrm{NMe}_{2}$. Michael addition reactions to the vinylidene double bond. Eur. J. Inorg. Chem. 2011:1824-1832.

11. For the synthesis of complex I, see: Hiraki K, Fuchita Y, Uchiyama T. Cyclopalladation of benzyldiphosphine by palladium (II) acetate. Inorg. Chim. Acta. 1982; 69:187-190. For the synthesis of complex J, see: (b) Bohm VP, Herrman WA. Mechanism of Heck Reaction Using a Phosphapalladacycle as the Catalyst: Classical versus Palladium (IV) Intermediates. Chem. Eur. J. 2001; 7:4191-4197. [PubMed: 11686598] For the synthesis of complex K, see: (c) Wu L, Hartwig JF. Mild palladium-catalyzed selective monoarylation of nitriles. J. Am. Chem. Soc. 2005; 127:15824-15832. [PubMed: 16277525] For the synthesis of complex L, see: (d) Dupont J, Gruber AS, Fonsesca GS, Monterio AL, Ebeling G, Burrow RA. Synthesis and catalytic properties of configurationally stable and non-racemic sulfur-containing palladacycles. Organometallics. 2001; 20:171-176.

12. The role of the $\mathrm{CsF}$ consists in releasing the free $\mathrm{P}(t-\mathrm{Bu})_{3}$ ligand from its air-stable $\mathrm{HBF}_{4}$ salt, see: Fu GC, Netherton MR. Air-stable Trialkylphosphonium salts: simple, practical, and versatile replacements for air-sensitive trialkylphosphines. Applications in stoichiometric and catalytic processes. Org. Lett. 2001; 3:4295-4298. [PubMed: 11784201]

13. The reported ${ }^{31} \mathrm{P}$ NMR signal for $\operatorname{Pd}\left[\left(\mathrm{P}(t-\mathrm{Bu})_{3}\right]_{2}\right.$ is $84.8 \mathrm{ppm}$, see: Mitchell EA, Baird MC. Optimization of Procedures for the Syntheses of Bis-phosphinoepalladium (0) recursors for Suzuki-Miyaura and Similar Cross-Coupling Catalysis; Identification of $3: 1$ Coordination Compounds in Catalyst Mixtures Containing $\mathrm{Pd}(0) \mathrm{PCy}_{3}$ and/or $\mathrm{PMeBu}_{2}{ }_{2}$. Organometallics. 2007; 26:5230-5238.

14. The reported ${ }^{31} \mathrm{P}$ NMR signal for complex $\mathbf{K}$ (Figure 3) is $-7.8 \mathrm{ppm}$, see: reference 11c.

15. Wassenaar J, Jansen E, van Zeist WJ, Bickelhaupt FM, Siegler MA, Spek AL, Reek JNH. Catalyst selection based on intermediate stability measured by mass spectrometry. Nature Chemistry. 2010; 2:417-421.

16. The reported ${ }^{31} \mathrm{P}$ NMR signal for $\mathrm{P}(t-\mathrm{Bu})_{3}$ is $63 \mathrm{ppm}$ and for $\mathrm{P}(=\mathrm{O})(t-\mathrm{Bu})_{3}$ is $-41 \mathrm{ppm}$ see: Tebby JC. Handbook of Phosphorus-31 Nuclear Magnetic Resonance Data. 1991Boca RatonCRC Press

17. Ahmar M, Barieux JJ, Cazes B, Gore J. Carbopalladation of allenic hydrocarbons: A new way to functionalized styrenes and 1,3-butadienes. Tetrahedron. 1987; 43:513-526.

18. Gai X, Grigg R, Ramzan MI, Sridharan V, Collard S, Muir JE. Pyrazole and benzothiazole palladacycles: stable and efficient catalysts for carbon-carbon bond formation. Chem. Communn. 2000:2053-2054.

19. Moreaou JL, Gauclemar M. Action des organomagnesiens sur les ethers-oxydes propargyliques en presence de bromure cuivreux: synthese de carbures alleniques. J. Organomet. Chem. 1976; 108:159-164.

20. Manhas MS, Ghosh M, Bose AK. Studies on lactams. Part 84. $\beta$-Lactams via a, $\beta$-unsaturated acid chlorides: intermediates for carbapenem antibiotics. J. Org. Chem. 1990; 55:575-580. 


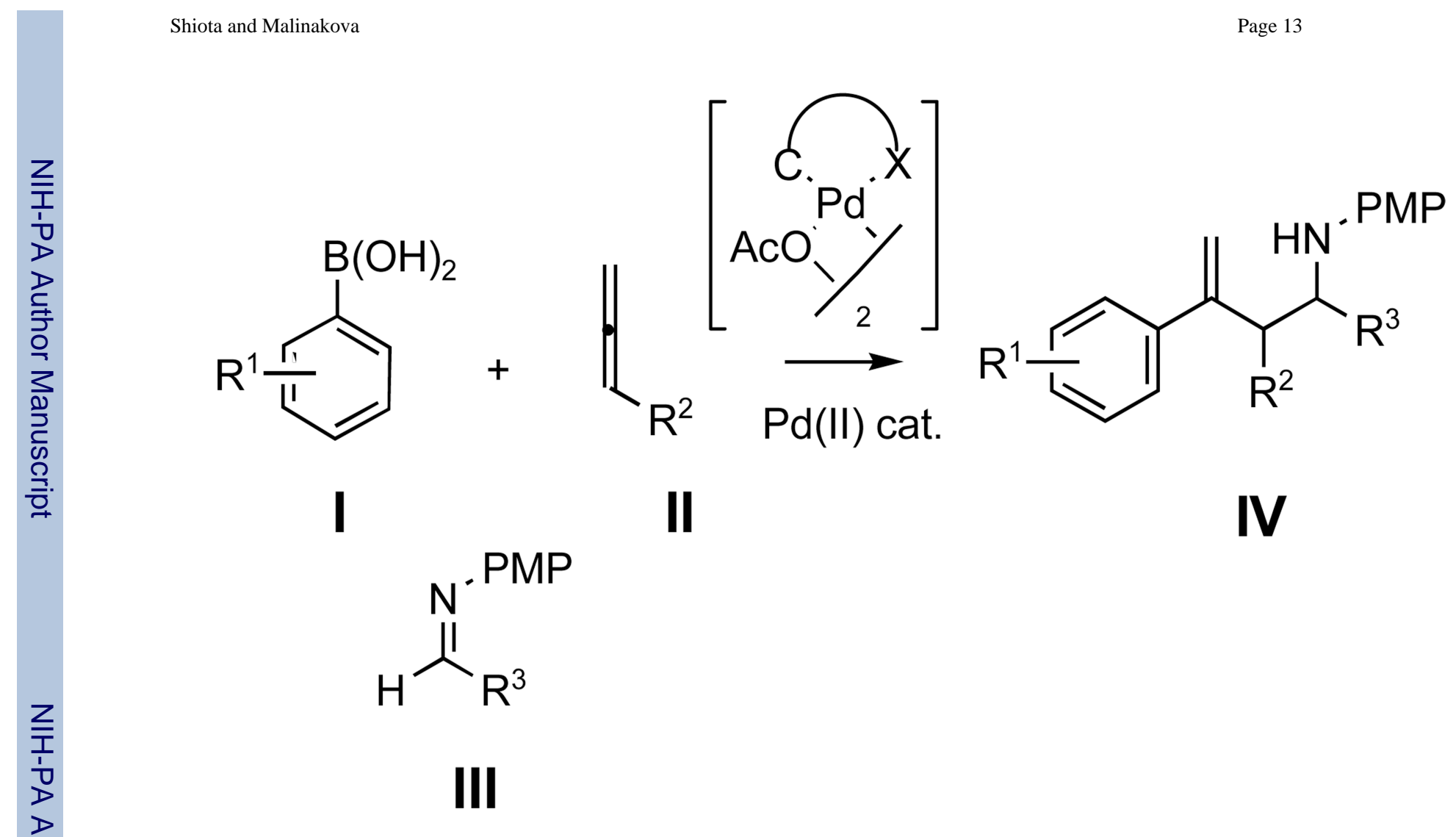

Fig. 1.

General overview of the pallada(II)-cycle-catalyzed three-component coupling 

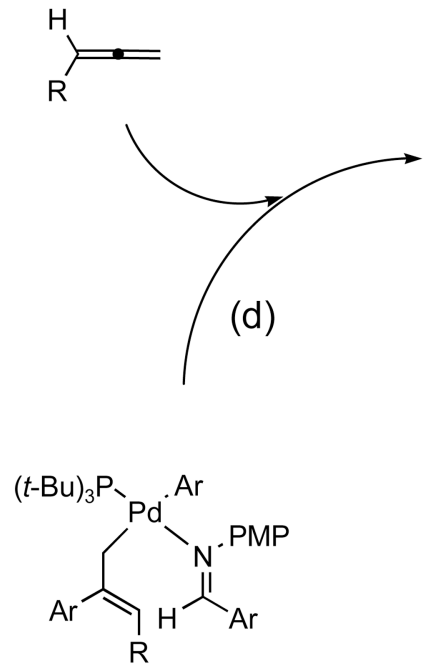

(c)
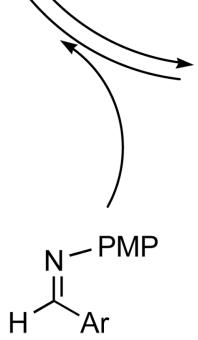
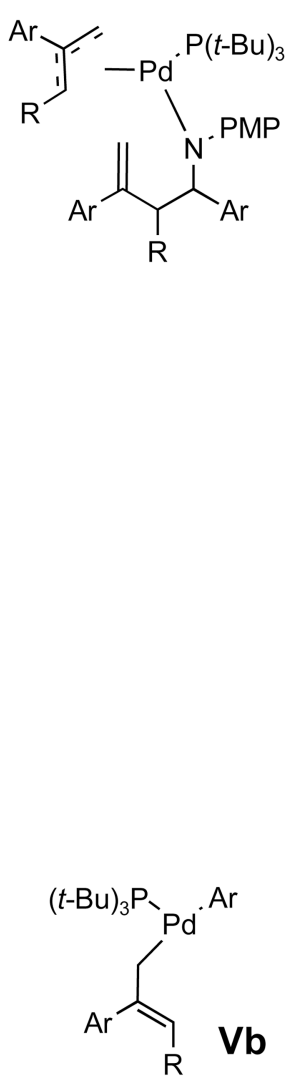

$(t-\mathrm{Bu})_{3} \mathrm{P}_{\mathrm{Pd}_{\mathrm{P}}} \mathrm{Ar}$

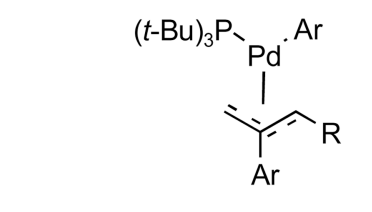

(a)

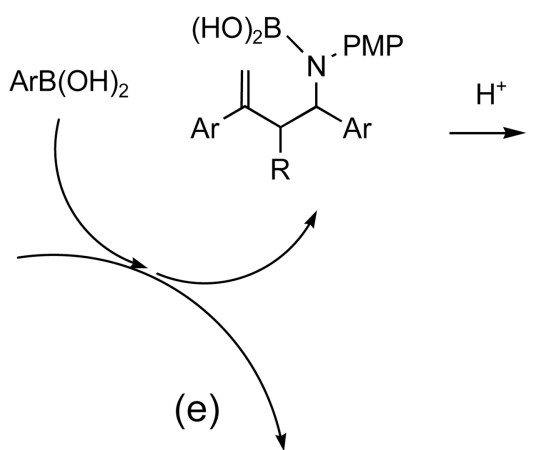

(b)

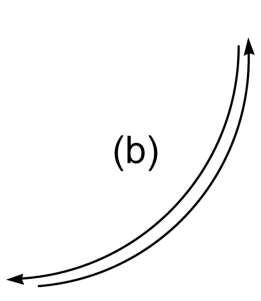<smiles>[Y10]NC([Al])C([R])C(=C)[AlH2]</smiles>

$\mathrm{Pd}(\mathrm{OAc})_{2}$

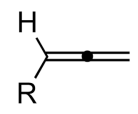

$\operatorname{ArB}(\mathrm{OH})_{2}$

$\mathrm{H}\left[\mathrm{P}(t-\mathrm{Bu})_{3} \mathrm{BF}_{4}\right] / \mathrm{CsF}$

Fig. 2.

Catalytic cycle proposed for reactions catalyzed by $\mathrm{Pd}(\mathrm{OAc})_{2}$ 
<smiles>CC1CCCOP1CCCCCO</smiles>
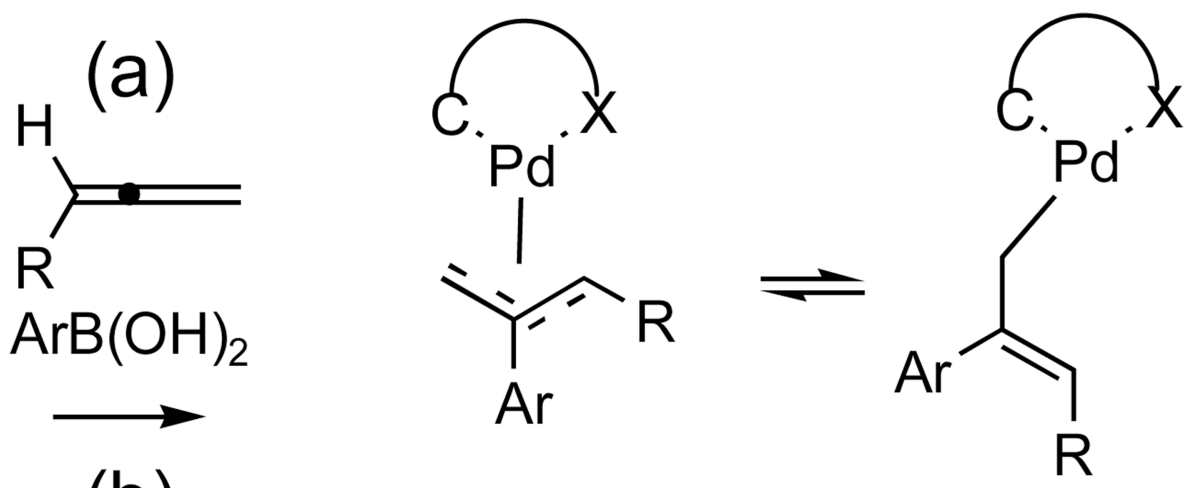

(b)

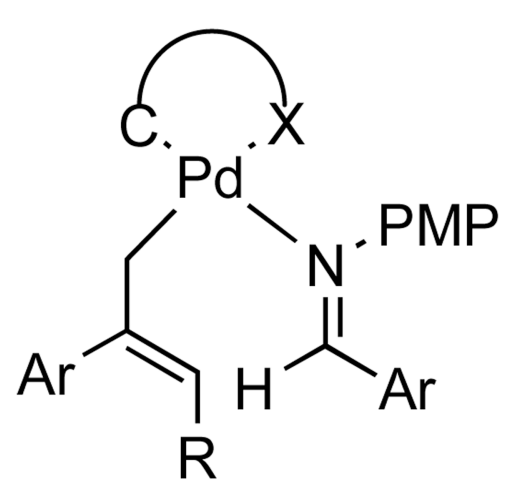

(c)

Vla

VIb

\section{VII}

Fig. 3.

Intermediates proposed for reactions catalyzed by (C-X)Pd(II) palladacycles 


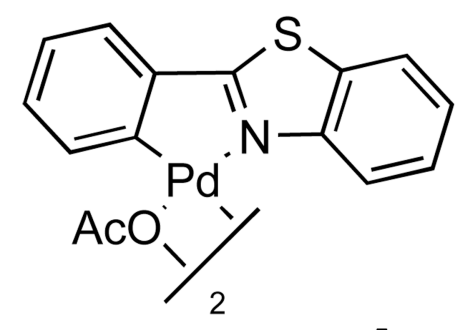

A<smiles></smiles><smiles>CC1CCCO1</smiles>
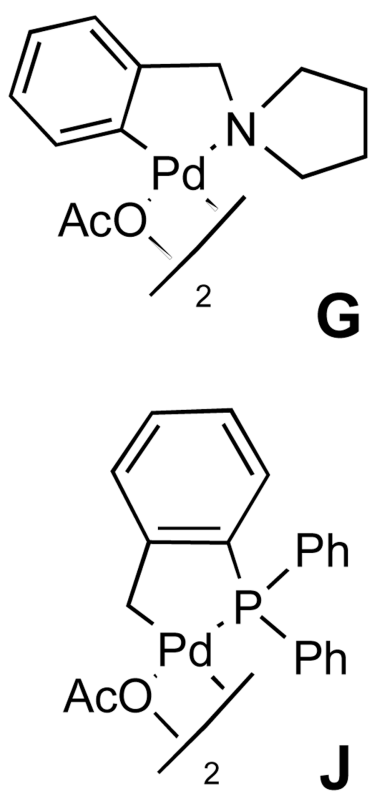
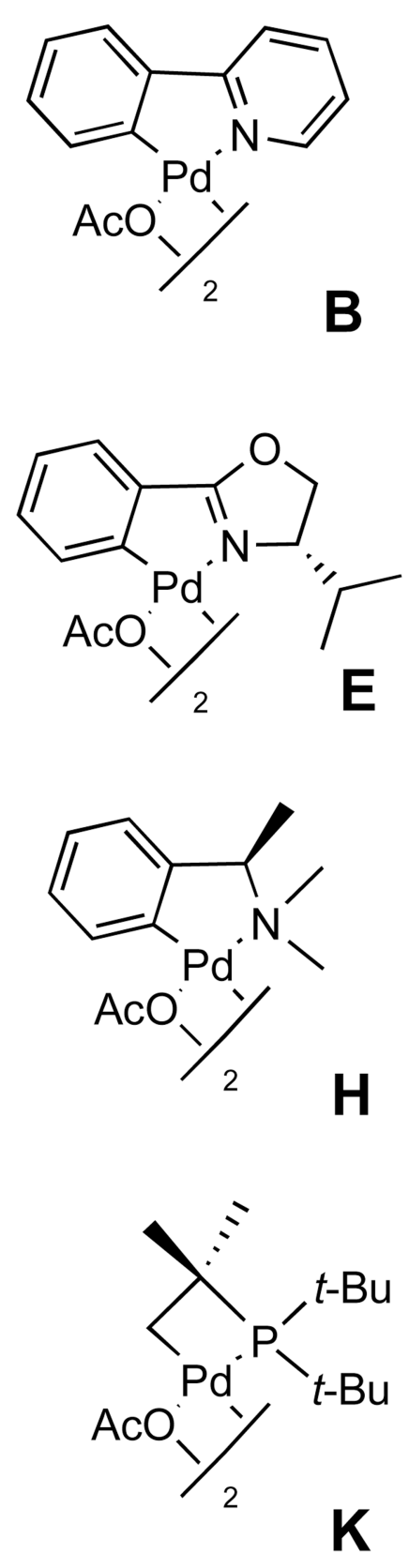
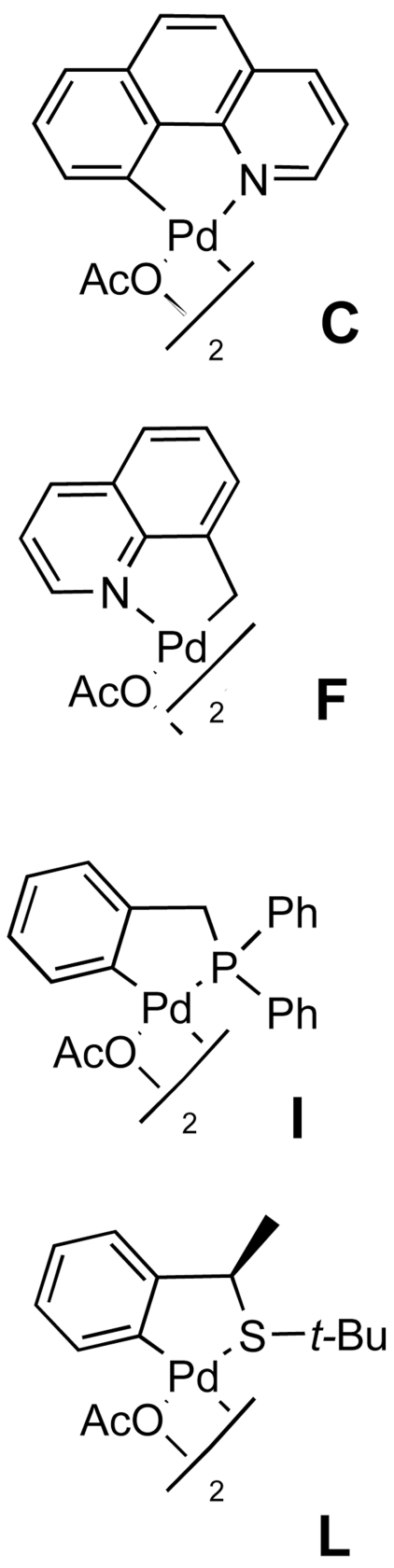

Fig. 4.

Cyclopalladated complexes 
(a) ${ }^{31} \mathrm{P}$ NMR monitoring (160 MHz, THF-d8) trace for the reaction of $\mathrm{Pd}(\mathrm{OAc})_{2}$ (1 equiv) with 1 a ( 2 equiv), 2 ( 5 equiv), 3a (1 equiv), $\mathrm{HP}(t-\mathrm{Bu})_{3} \mathrm{PBF}_{4}(1 \mathrm{~mol}$ equiv) and $\mathrm{CsF}$ (4 equiv)

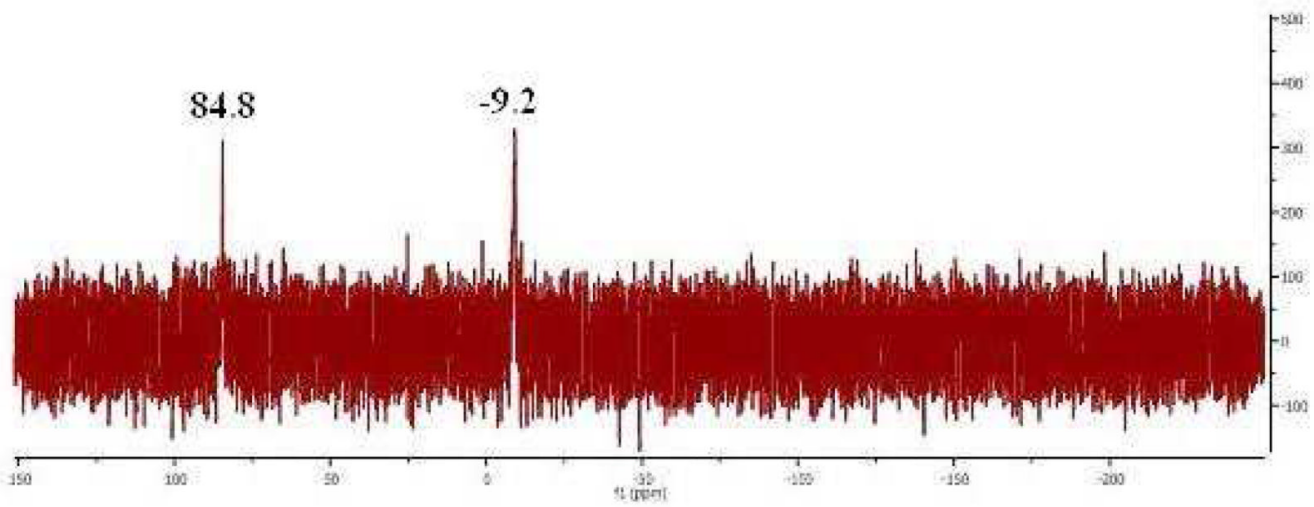

(b) ${ }^{31}$ P NMR monitoring (160 MHz, THF-d8) trace for the reaction of complex $\mathbf{A}$ (1 equiv), with $1 \mathbf{a}$ ( 2 equiv), 2 ( 5 equiv), $\mathbf{3 a}$ ( 1 equiv), $\mathrm{HP}(t-\mathrm{Bu})_{3} \mathrm{PBF}_{4}$ ( 1 mol equiv) and $\mathrm{CsF}$ ( 4 equiv)

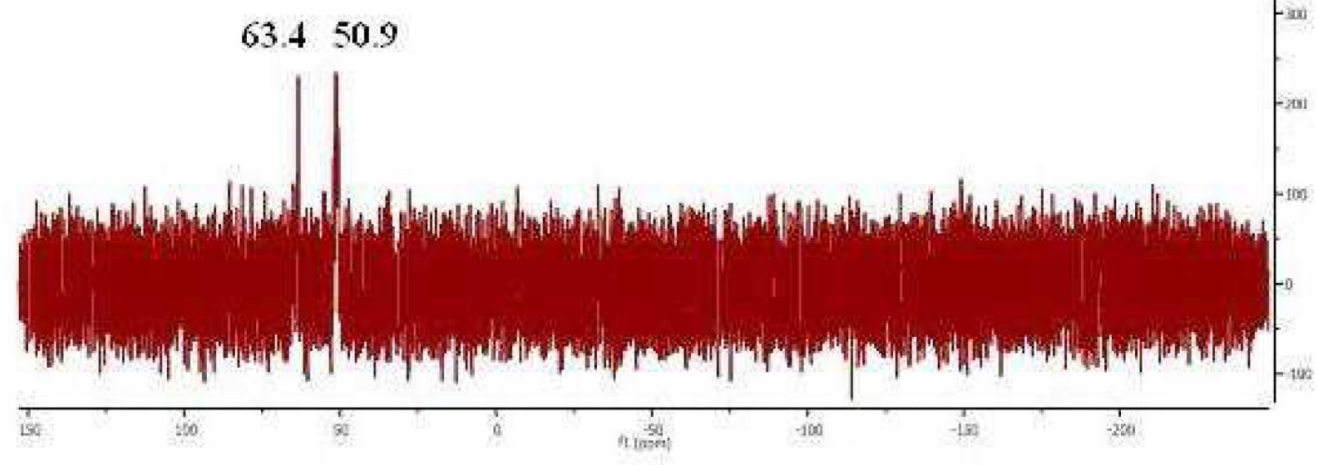

Fig. 5.

${ }^{31}$ P NMR monitoring experiments 

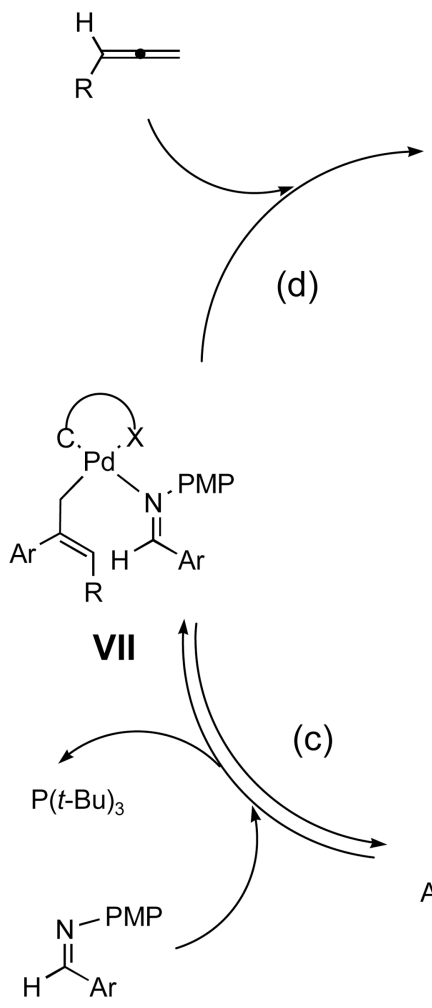
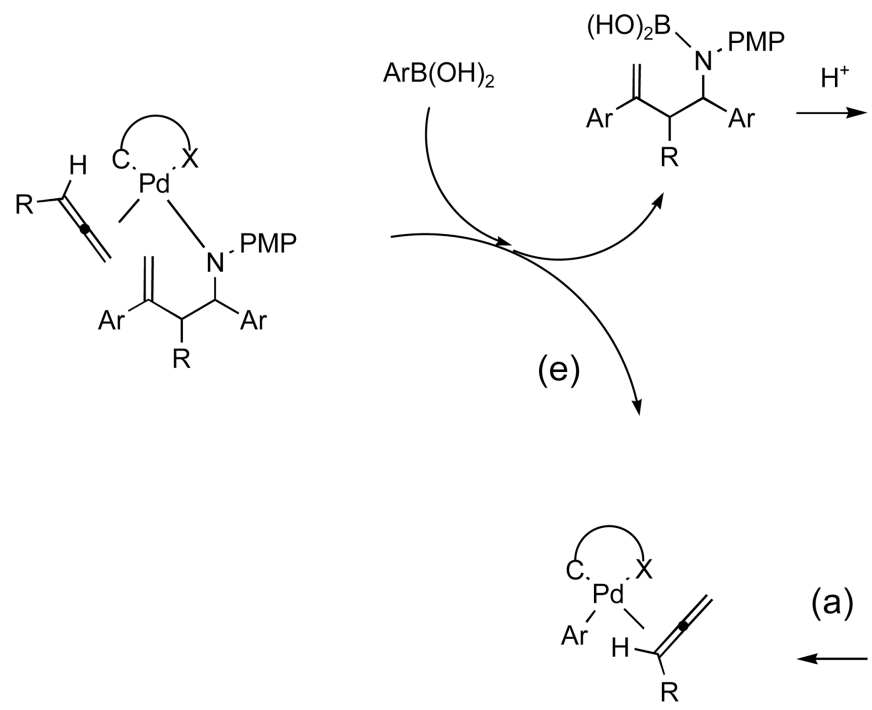

(a)

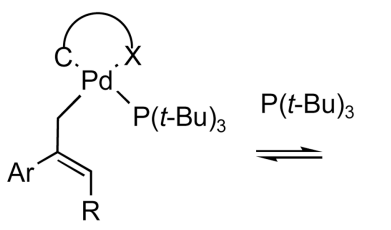

VIb

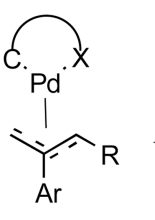

Vla

Fig. 6.

Catalytic cycle for reactions catalyzed by complex $\mathbf{A}$ with $\mathrm{P}(t-\mathrm{Bu})_{3}$ ligand 

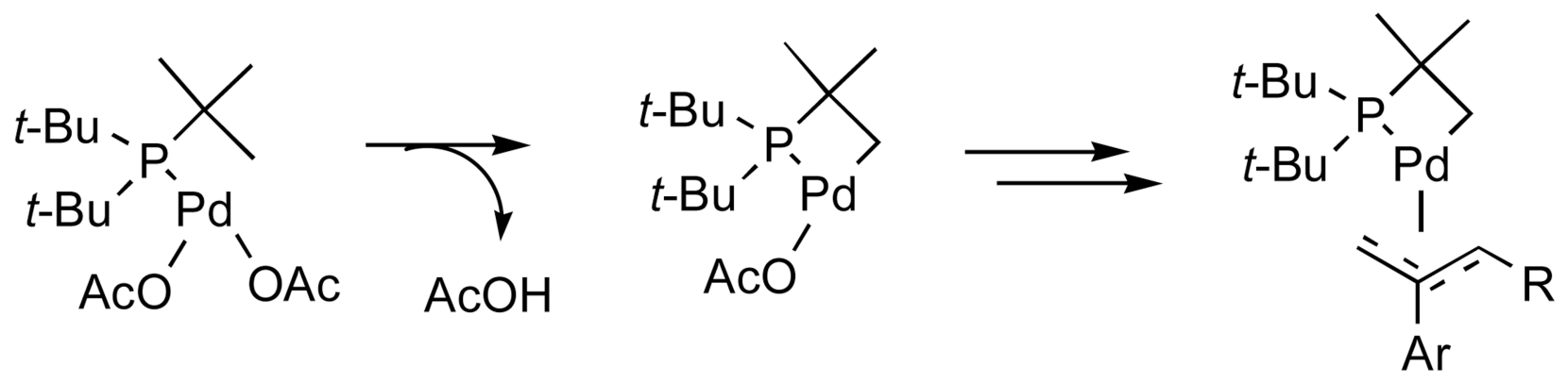

VIII

Fig. 7.

A proposed intermediate limiting the effectiveness of the $\mathrm{Pd}(\mathrm{OAc})_{2}$ catalyst 


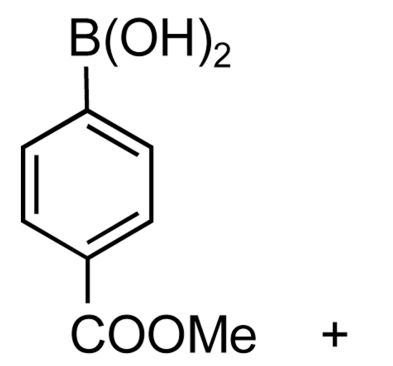

1a<smiles>[Mg]=N/N=C\c1ccccc1</smiles>

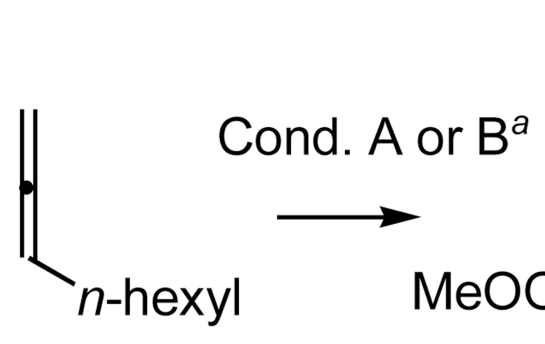

2

Catalyst A
$4 a(6 \%)$

$4 a(44 \%)$

$4 a(18 \%)$

$4 a(73 \%)$

$4 a(76 \%)$

$4 a(61 \%)$

Scheme. 1.

Optimization of conditions for the reaction catalyzed by the pallada(II)cycle $a$ Cond. A: 1a : $2: 3 \mathbf{a}=2: 5: 1$ (mol equiv.), THF, $40{ }^{\circ} \mathrm{C}, 16 \mathrm{~h}, 10 \mathrm{~mol} \% \mathrm{Pd}$ as complex A, $\mathrm{L}\left(\mathrm{PR}_{3}\right)(10 \mathrm{~mol} \%), \mathrm{CsF}$ (4 equiv). Cond. B: same as Cond. A except $10 \mathrm{~mol} \% \mathrm{Pd}$ as $\mathrm{Pd}(\mathrm{OAc})_{2}, \mathrm{HP}\left(t-\mathrm{Bu}_{3}\right) \mathrm{BF}_{4}(10 \mathrm{~mol} \%)$ 
Table 1

Comparison of the performance of different pallada(II)cycles as catalysts

\begin{tabular}{|c|c|c|}
\hline \\
\hline $3 \mathbf{a}$
\end{tabular}

${ }^{a}$ Cond. 1a : $2: 3 a, 2: 5: 1$ (mol equiv), THF, $40{ }^{\circ} \mathrm{C}, 24 \mathrm{~h}$, Pd catalyst (10 mol $\left.\%\right), \mathrm{HP}(t-\mathrm{Bu}) 3 \mathrm{BF} 4$ (10 mol $\left.\%\right)$, CsF (4 equiv).

${ }^{b}$ Enantiomeric excess (\%) measured by chiral phase HPLC. 
Table 2

Survey of the reaction scope with substituted boronic acids

\begin{tabular}{|c|c|c|c|c|}
\hline $\begin{array}{l}\mathrm{B}(\mathrm{OH}) \\
\mathrm{R} \\
\text { 1a-g }\end{array}$ & $\overbrace{3 a}^{N_{1}^{-P N}}$ & Cond. $^{\text {a }}$ & \multicolumn{2}{|c|}{${ }_{4 \mathbf{a}-\mathbf{g}}$} \\
\hline entr & $\begin{array}{l}\text { substrate } 1 \\
\text { (R) }\end{array}$ & catalyst & $\begin{array}{c}\text { prdt } \\
4\end{array}$ & $\begin{array}{c}\text { yield } \\
(\%)\end{array}$ \\
\hline 1 & \multirow[t]{2}{*}{ 4- $\mathrm{MeOOCC}_{6} \mathrm{H}_{4^{-}}$} & $\mathrm{Pd}(\mathrm{OAc})_{2}$ & \multirow[t]{2}{*}{$4 a$} & 61 \\
\hline 2 & & A & & $\begin{array}{c}76 \\
(+15)\end{array}$ \\
\hline 3 & \multirow[t]{2}{*}{$4-\mathrm{MeOC}_{6} \mathrm{H}_{4}-$} & $\mathrm{Pd}(\mathrm{OAc})_{2}$ & \multirow[t]{2}{*}{$4 b$} & 48 \\
\hline 4 & & $\mathbf{A}$ & & $\begin{array}{c}64 \\
(+16)\end{array}$ \\
\hline 5 & \multirow[t]{2}{*}{$4-\mathrm{MeCOC}_{6} \mathrm{H}_{4-}^{-}$} & $\mathrm{Pd}(\mathrm{OAc})_{2}$ & \multirow[t]{2}{*}{$4 c$} & 43 \\
\hline 6 & & A & & $\begin{array}{c}77 \\
(+34)\end{array}$ \\
\hline 7 & \multirow[t]{2}{*}{ 4- $\mathrm{CNC}_{6} \mathrm{H}_{4^{-}}$} & $\mathrm{Pd}(\mathrm{OAc})_{2}$ & \multirow[t]{2}{*}{$4 d$} & 30 \\
\hline 8 & & $\mathbf{A}$ & & $\begin{array}{c}54 \\
(+24)\end{array}$ \\
\hline 9 & \multirow[t]{2}{*}{ 4- $-\mathrm{FC}_{6} \mathrm{H}_{4^{-}}$} & $\mathrm{Pd}(\mathrm{OAc})_{2}$ & \multirow[t]{2}{*}{$4 e$} & 29 \\
\hline 10 & & $\mathbf{A}$ & & $\begin{array}{c}37 \\
(+8)\end{array}$ \\
\hline 11 & \multirow[t]{2}{*}{ 4- $\mathrm{ClC}_{4} \mathrm{H}_{4}^{-}$} & $\mathrm{Pd}(\mathrm{OAc})_{2}$ & \multirow[t]{2}{*}{$4 f$} & 54 \\
\hline 12 & & $\mathbf{A}$ & & $\begin{array}{c}56 \\
(+2) \\
\end{array}$ \\
\hline 13 & \multirow[t]{2}{*}{$4-\mathrm{MeC}_{6} \mathrm{H}_{4^{-}}$} & $\mathrm{Pd}(\mathrm{OAc})_{2}$ & \multirow[t]{2}{*}{$4 g$} & 56 \\
\hline 14 & & $\mathbf{A}$ & & $\begin{array}{c}58 \\
(+2)\end{array}$ \\
\hline
\end{tabular}

${ }^{a}$ Cond. 1a : 2 : 3a, $2: 5: 1$ (mol equiv), THF, $40{ }^{\circ} \mathrm{C}, 16 \mathrm{~h}$, Pd catalyst (10 mol $\left.\%\right), \mathrm{HP}(t$-Bu) $3 \mathrm{BF} 4$ (10 mol\%), CsF (4 equiv). 